
العدد العشرون لسنة 9 1 ـ ب م
090
مجلة البحث العلمى فى التربية

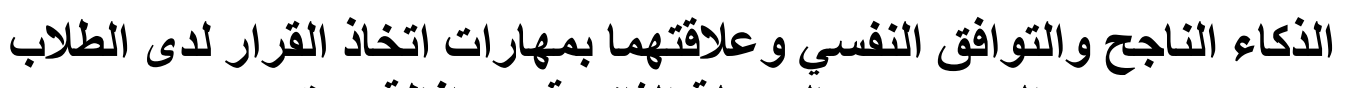

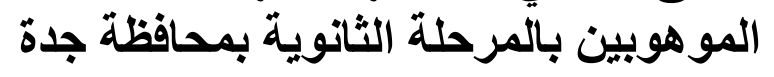

إعداد

أ. مصطفى مصطفى كامل خلف

باحث بقسم علم النفس التربوي ـ كلية التربية ـ جامعة المدينة العالمية ماية

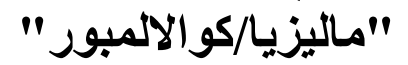




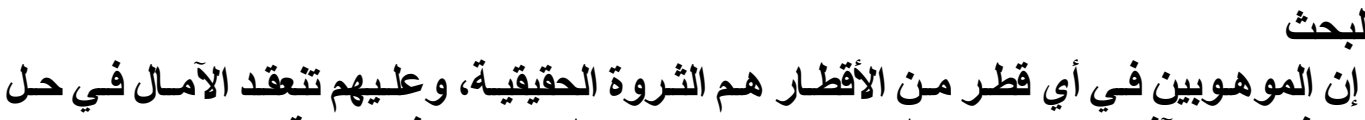

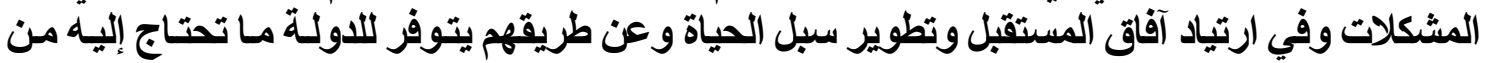

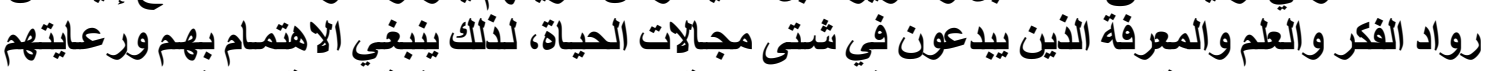

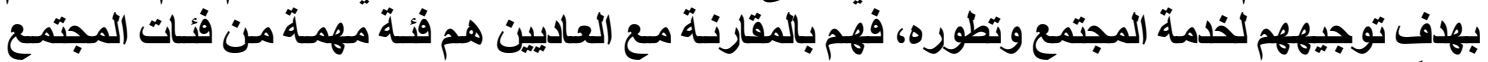

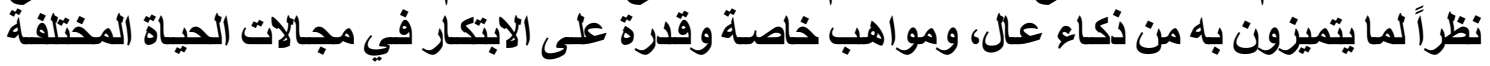

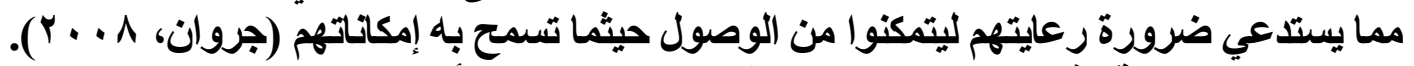

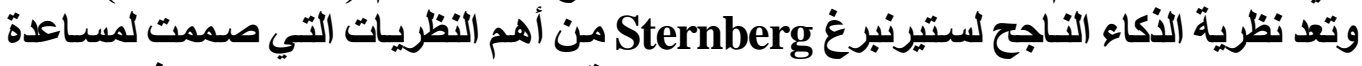

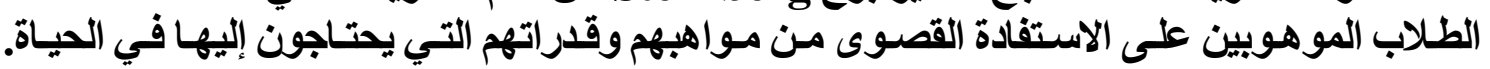

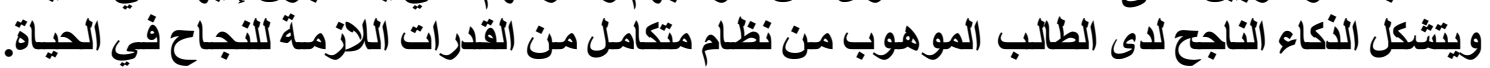

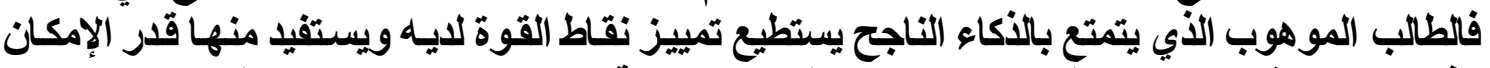

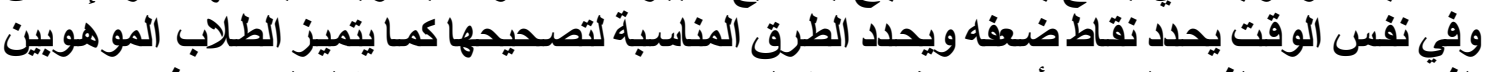

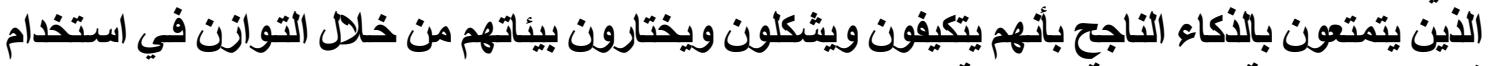

قدراتهم التحليلية والإبداعية والعملية (Sternberg, 2010).

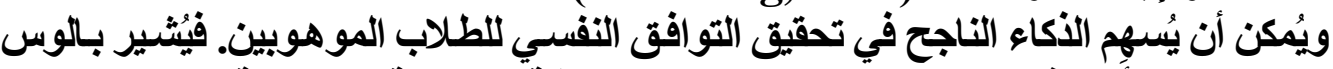
(Palos, 2013)

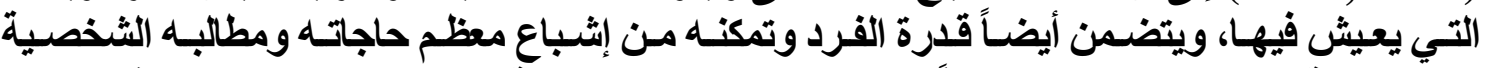

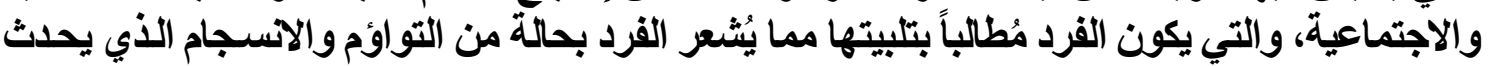
بينه وبين بيئته.

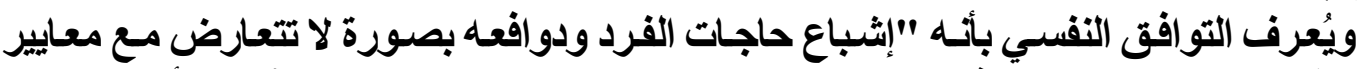

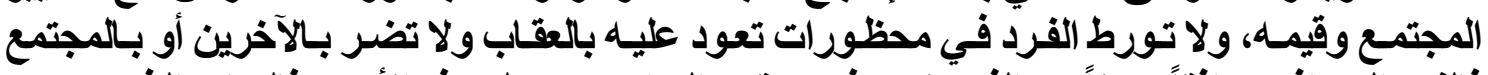

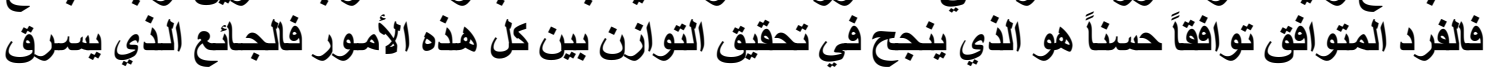

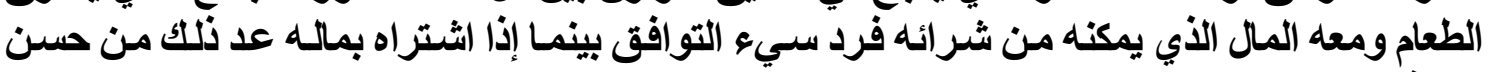
التوافق" (Peterson,2015).

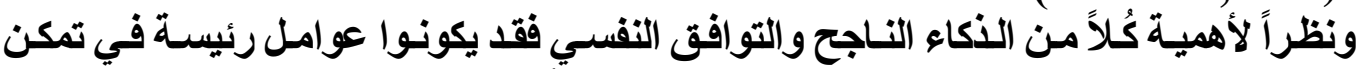

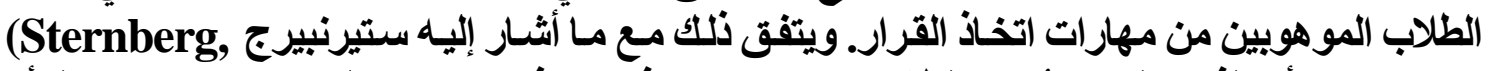

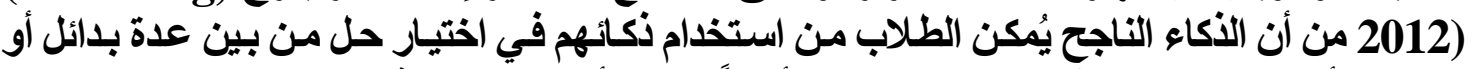

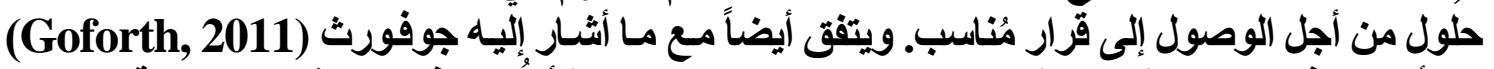

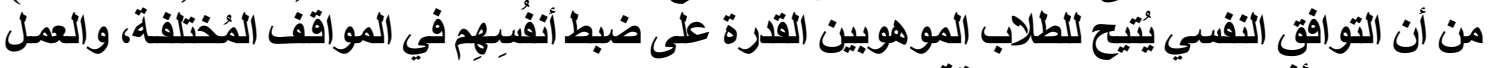

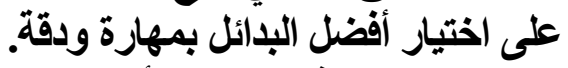

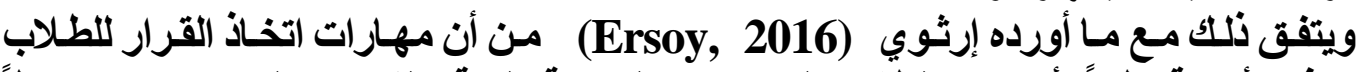

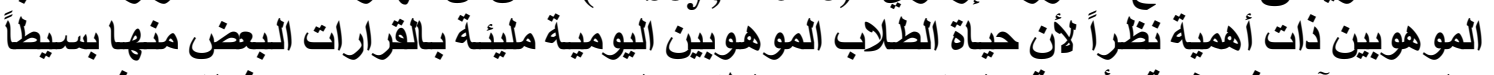

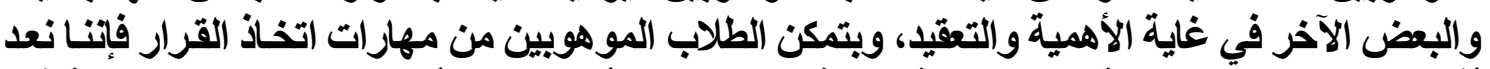

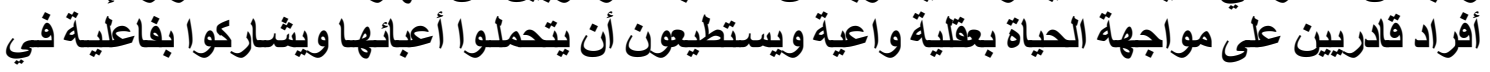
مشكلاتها.

ومن هنا تأتي أهمية دراسة الذكاء الناجح والتوافق النفسي وعلاقتهما بمهارات اتخاذ القرار

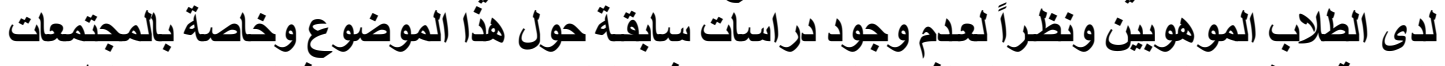

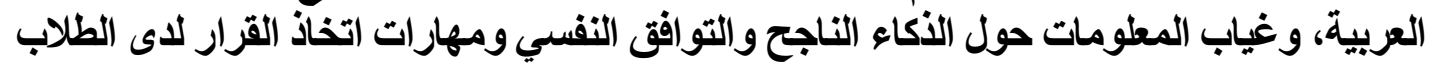

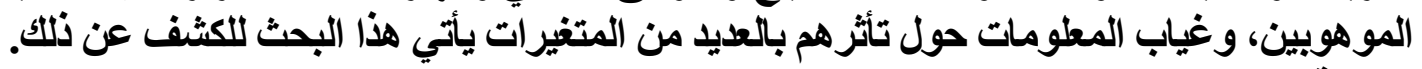


يقاس تطور الأمم ورقيها بالاهتمام الأي توليه لفئة الموهوبين فهم يمثلون ثروة حقيقية للبلاد

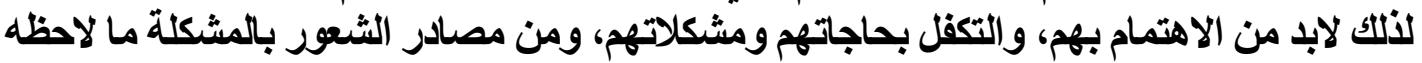

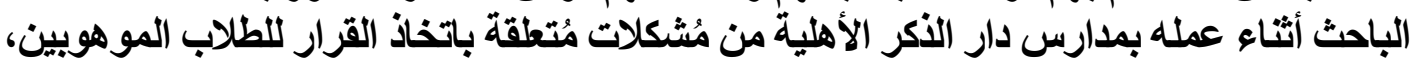

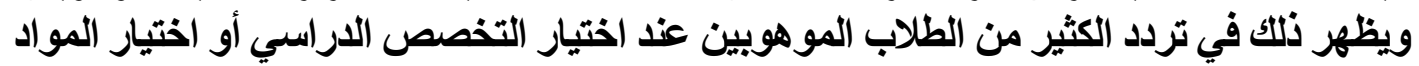

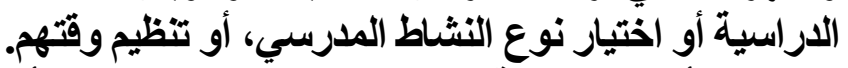

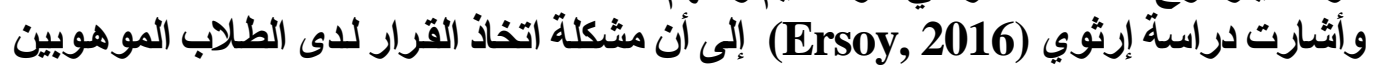

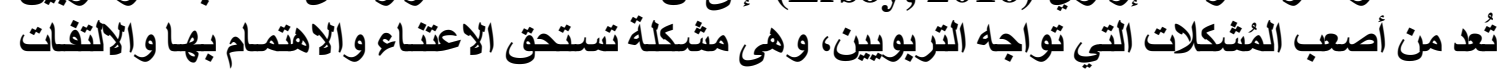

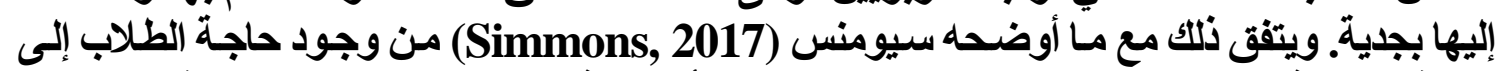

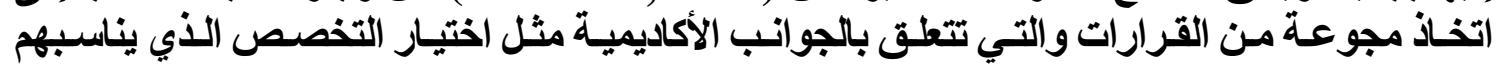

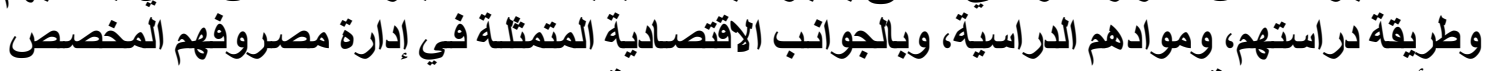

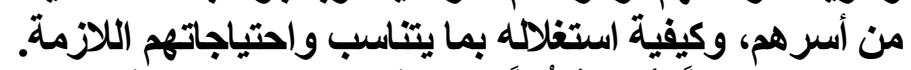

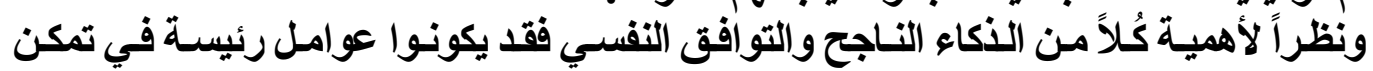

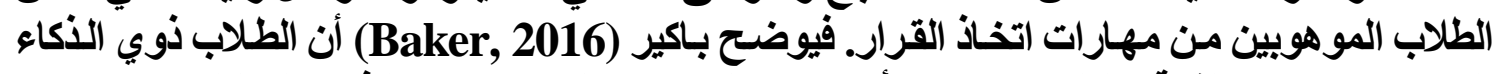

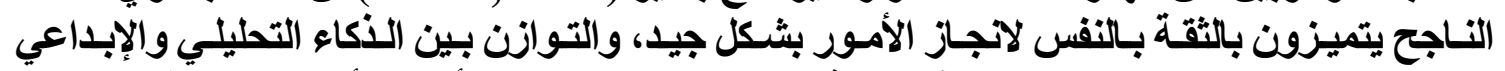

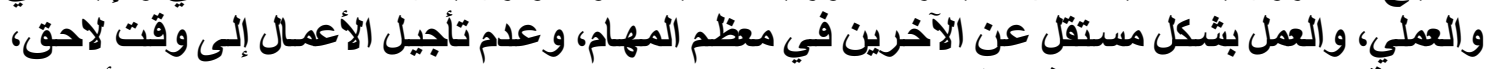

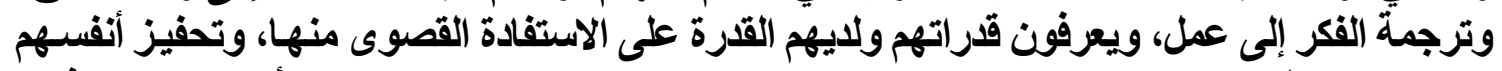

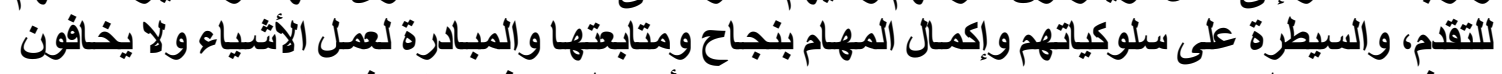

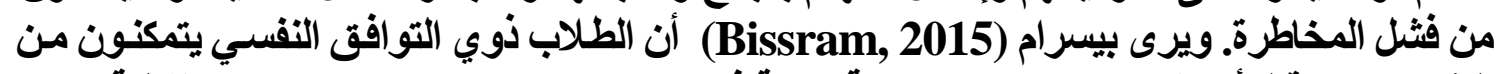

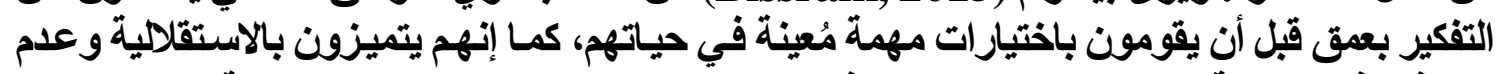

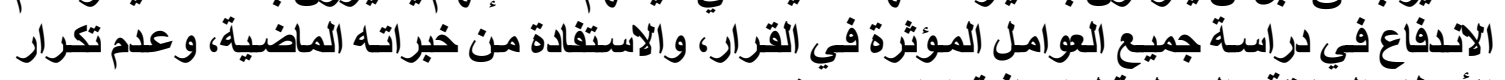

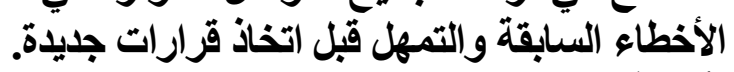
أسئلة البحثة البحنة

ا. هل توجد علاقة إرتباطية ذات دلالة إحصائية بين الأكاء الناجح ومهارات اتخاذ القرار لاى الطلاب

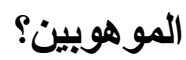
ץ. هل توجد علاقة إرتباطية ذات دلاية إحصائية بين التوافق التفسي ومهارات اتخاذ القرار لاى الطلاب الموهوبين

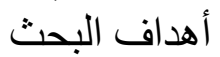

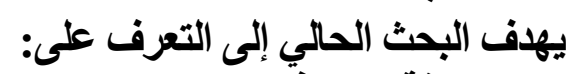

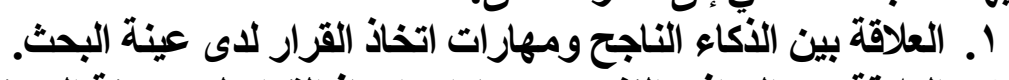

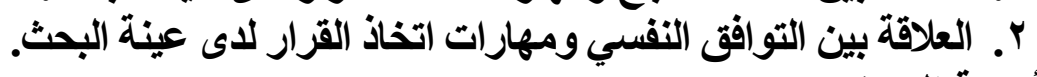
أهمبة البحث

يستمد البحث أهميته من أهمية الأكاء الناجح والتوافق النفسي ودورهم الفعال في مسـاعدة

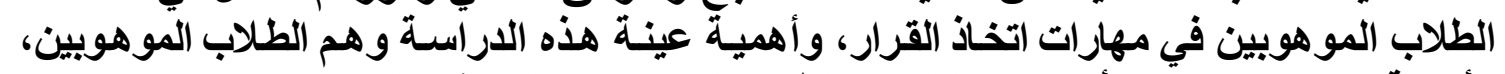

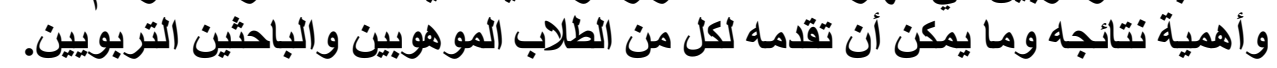
حدود البحث تحدد البحث الحالي بالحدود التبالية: ا 1

ا ـ تـم تحديـد عينـة الدراسـة الحاليـة بـ (7 9) طالب مـن الطـلاب الموهوبين بالمرحلـة الثانويـة بمدارس دار الأكر الأهلية بمحافظة جدة. 


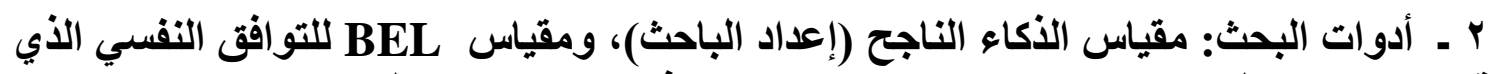

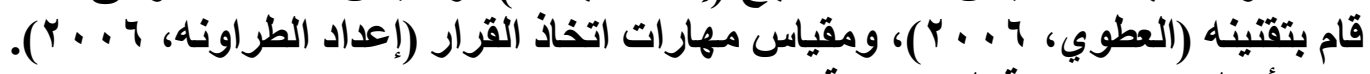
r ـ الأساليب الإحصائية المستخدمة.

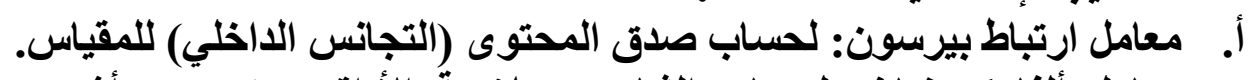

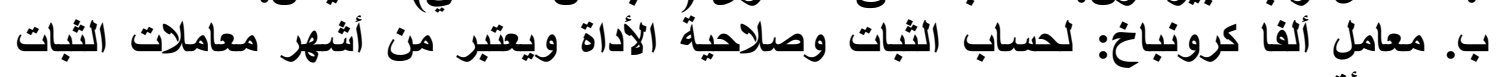

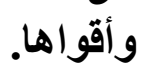

ج. استخام معامل ارتباط بيرسون pearson لتحديد العلاقة الارتباطيه بين متغيرات البحث.

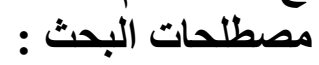
الذكاء النـاجح: مجموعة مـن القدرات التحليليـة والإبداعيـة والعمليـة التي يحتـاج إليها الطلاب المو هوبين.

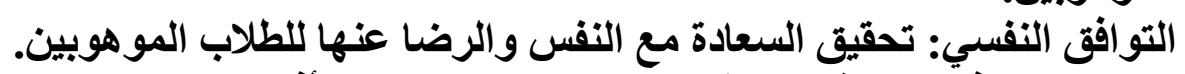

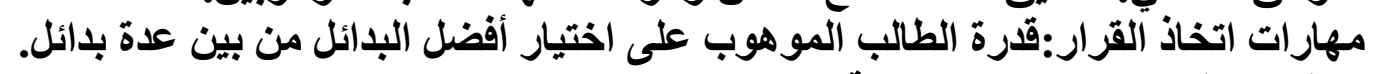
الإطار النظري والدراذ الأسات السابقة:

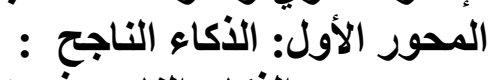

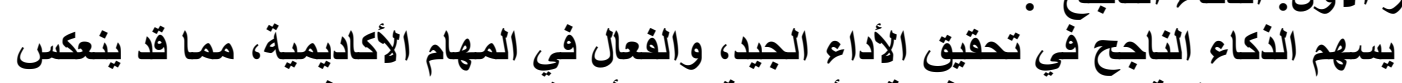

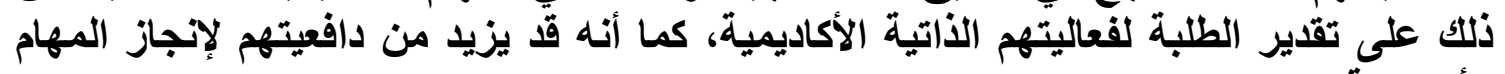

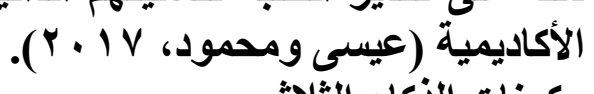

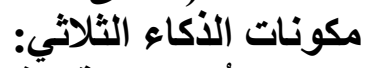

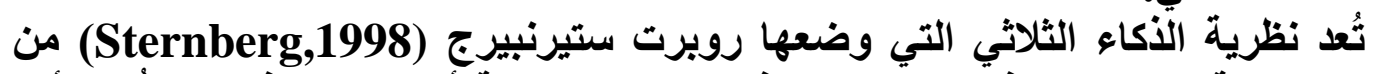

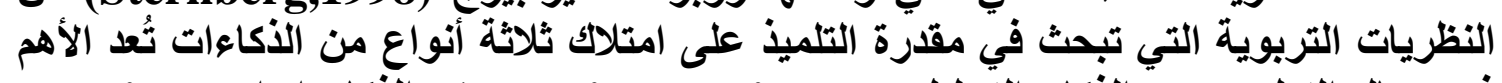

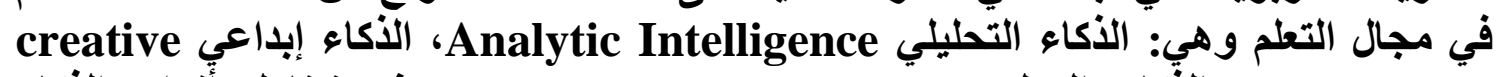
كالتئ الأكاء العملي Intelligence

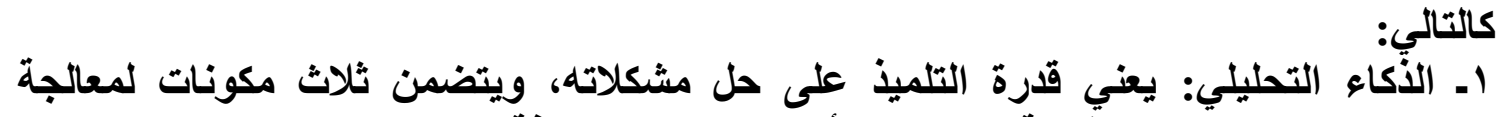

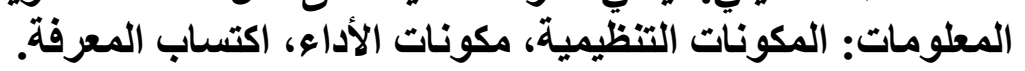

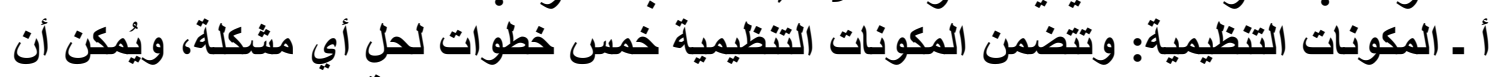

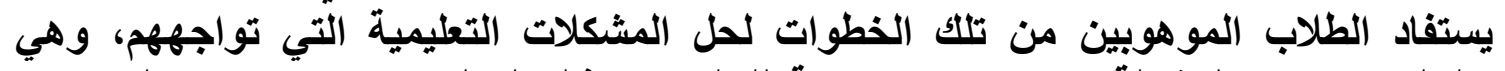

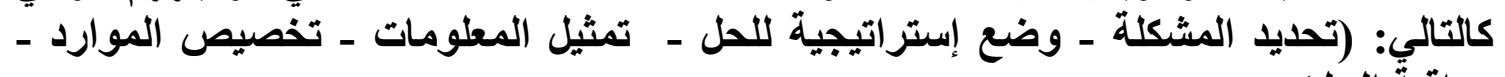
مراقبةًة (الحل).

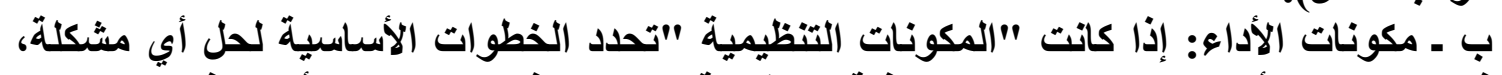

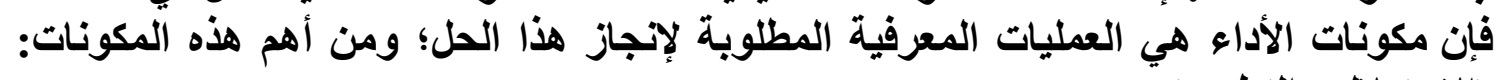

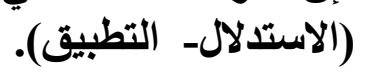

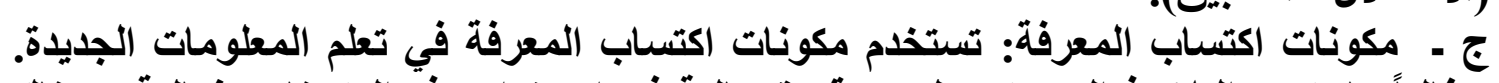

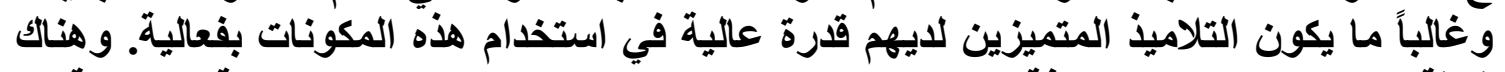

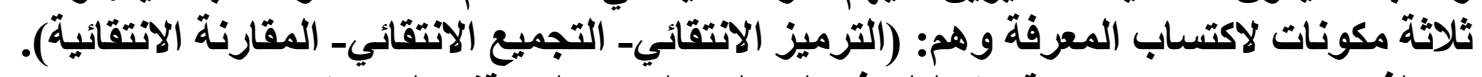

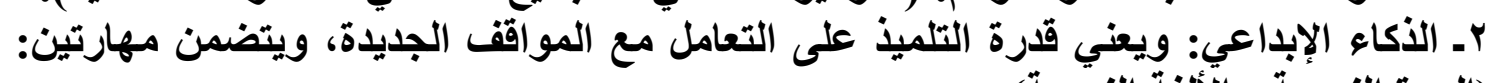
(الجدة النسبية ـ الألفة النسبية). كــ الذكاء العملي: يعني قدرة التلميذ على فهم وتحليل المواقف في الحياة اليومية والاستفادة

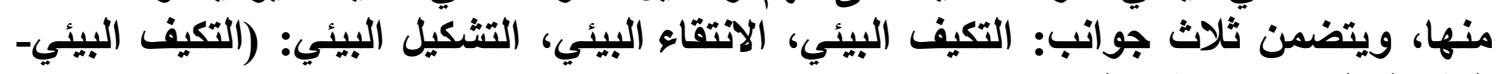
(التثكيل البيئي- الانتقاء البيئي)(Sternberg, 2010). 


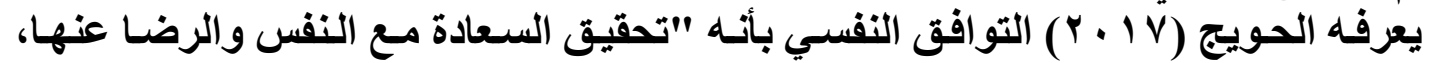

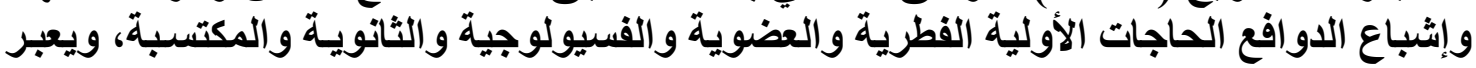
عن سلم داخلي حيث يقل الصراع الأب مع النفس ومئ الآخرين".

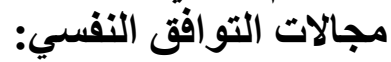

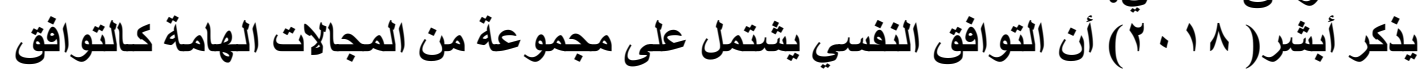

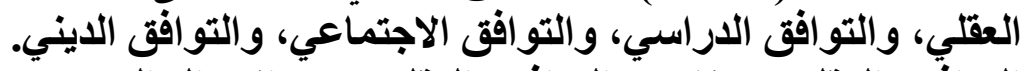

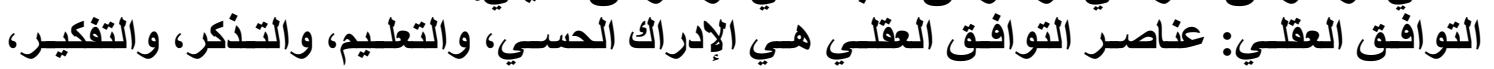

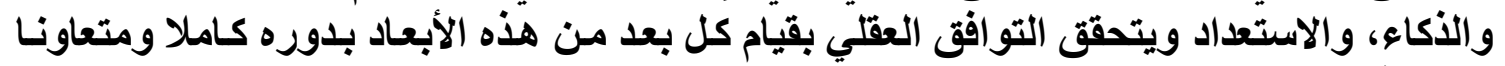

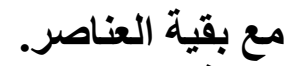

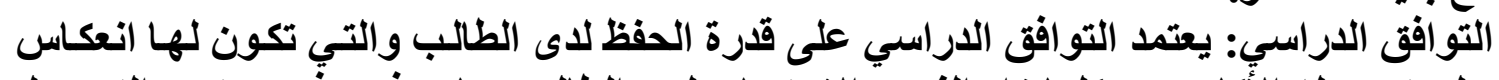

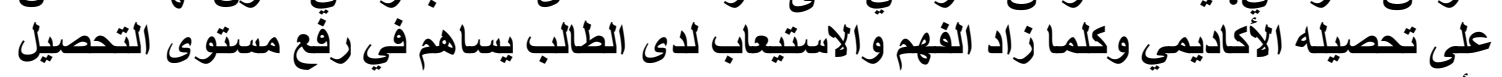
الأكاديمي والعكس صحيح.

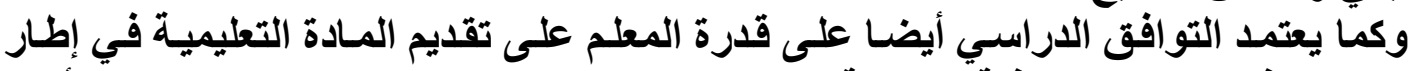

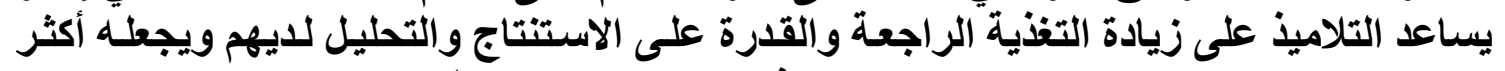

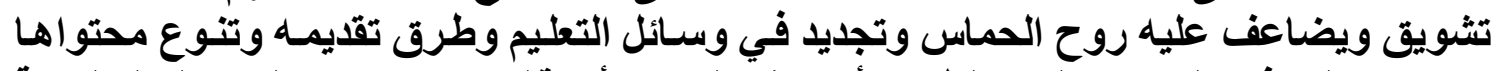

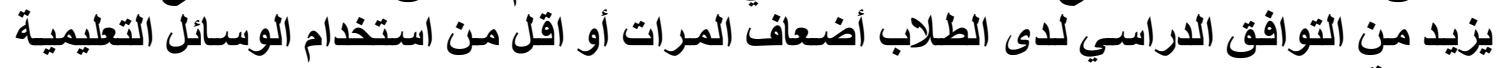

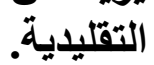

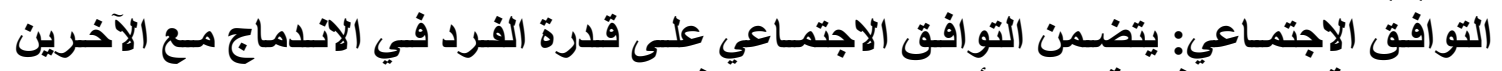

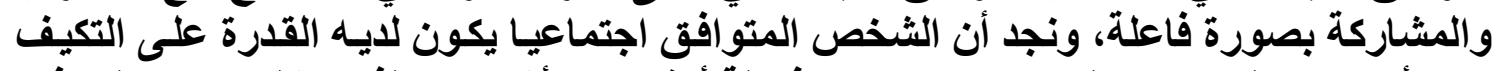

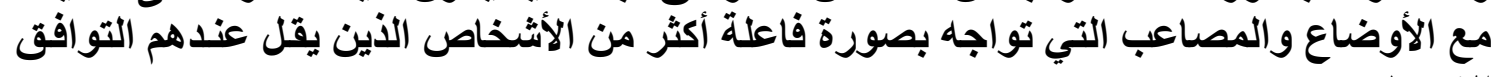

التوافق الديني: إما التوافق الايني فهو جزء من التركيب النفسي للفرد وكثيرا مـا يكون مسرحا

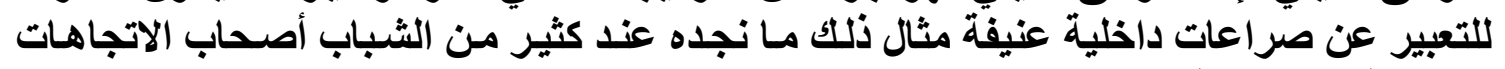
الإلحادية والتعصبية. المحور الثالث: التخاذ التهبة: القرار: مفهوم مهارات اتخاذ القزار:

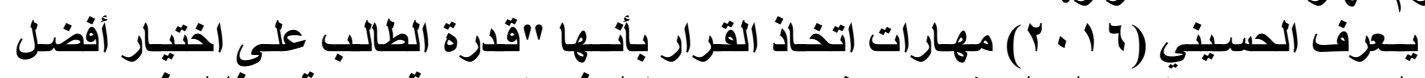

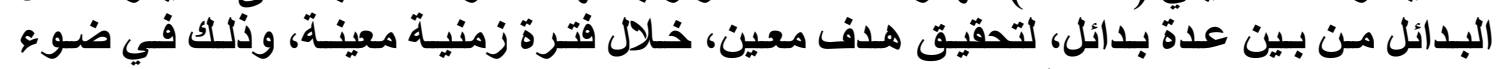
المطومات والمعطيات المتاحة". خطوات مهار ات اتخاذ التخات القرار:

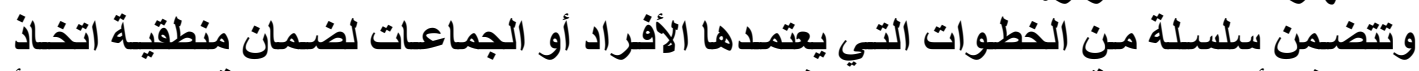

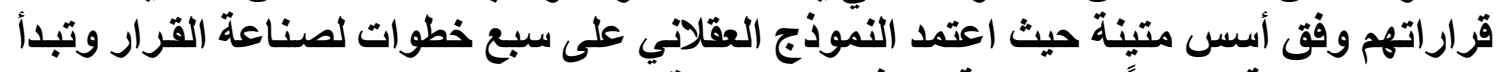

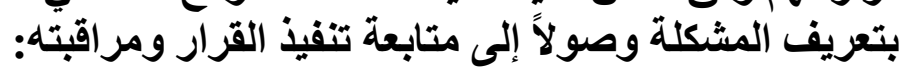

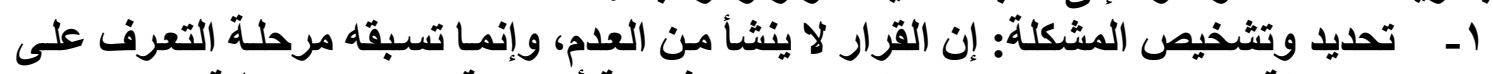

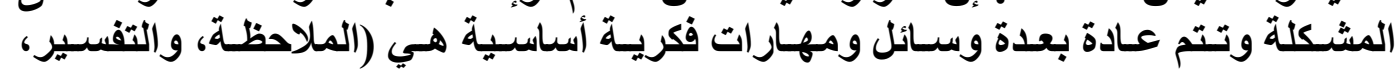
والتجسيا). r- صياغة الأهداف: وهي المرحلة التي تبدأ بمجرد انتهاء تعريف المشكلة أو تحديد أبعادهـا لمعالجتها من خلال أهداف محددة. 


$$
\text { مجلة البحث العلمى فى التربية }
$$

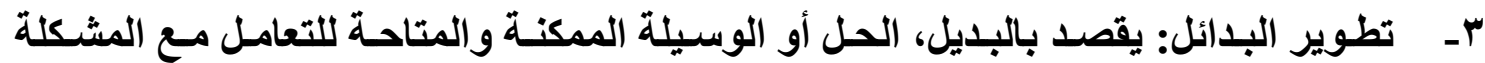

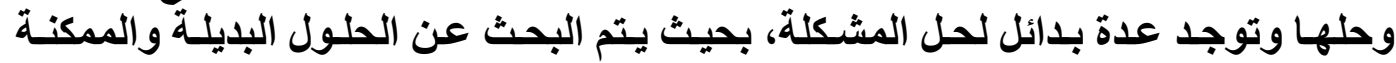

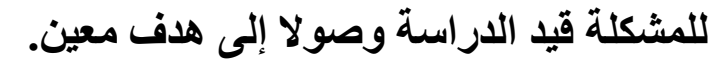

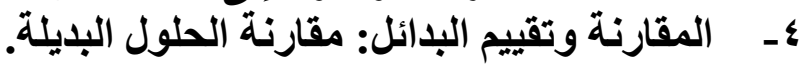

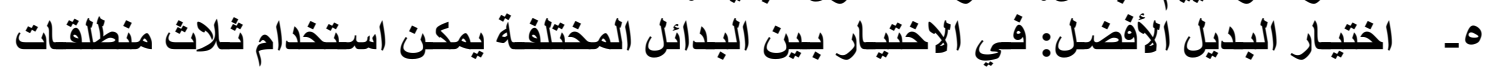

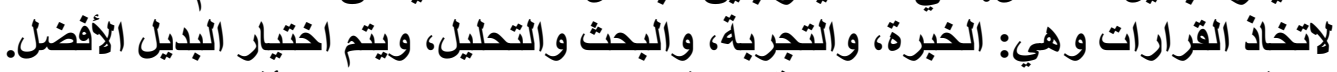

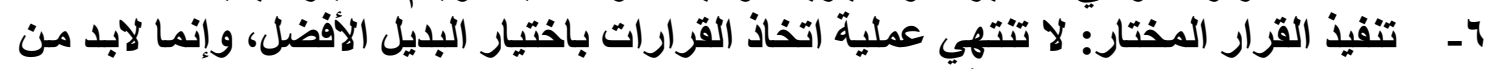

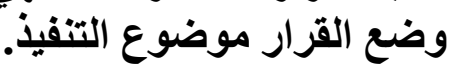

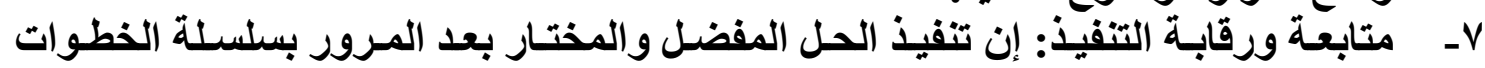

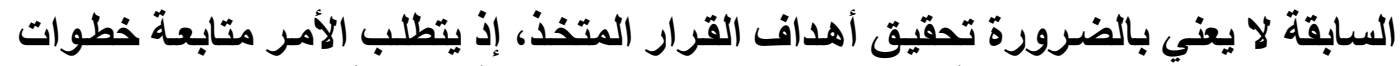

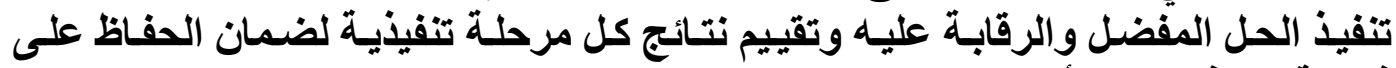

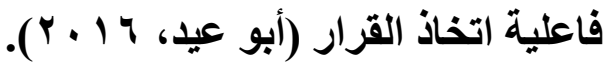

$$
\begin{aligned}
& \text { أهم الدراسات التي تناولت متغيرات البحث: البحث: }
\end{aligned}
$$

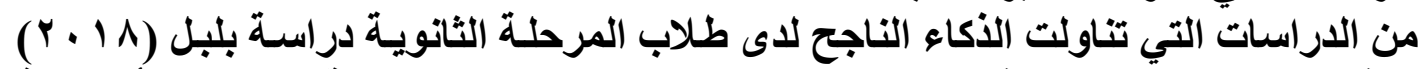

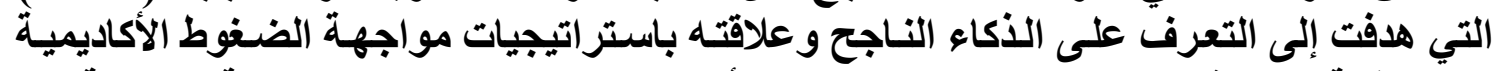

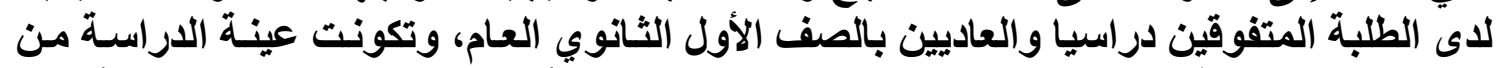

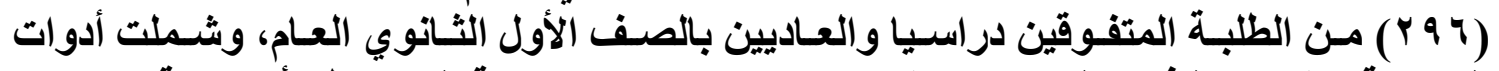

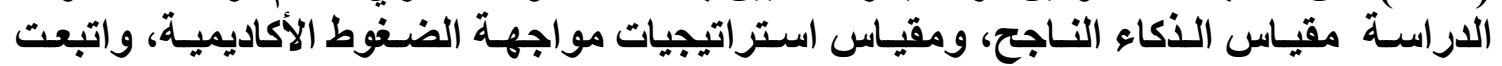

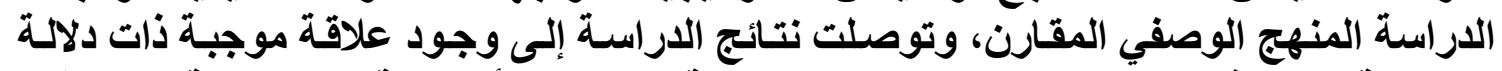

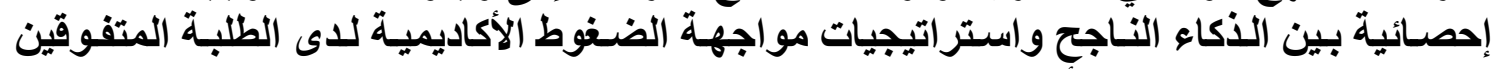

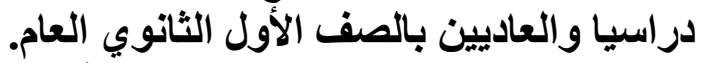

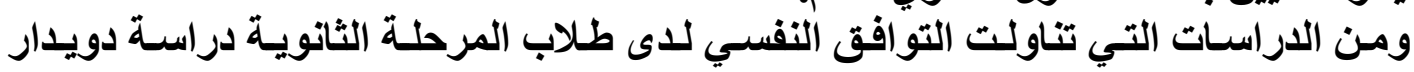

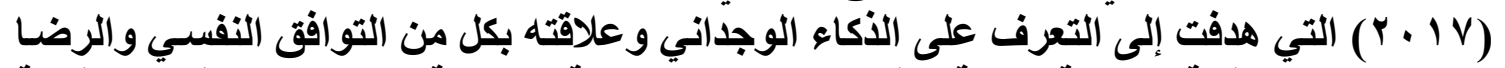

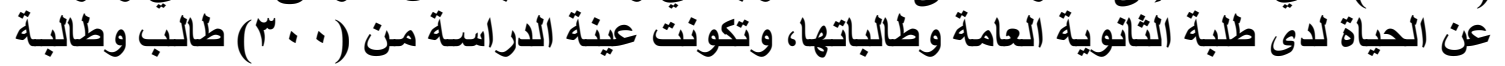

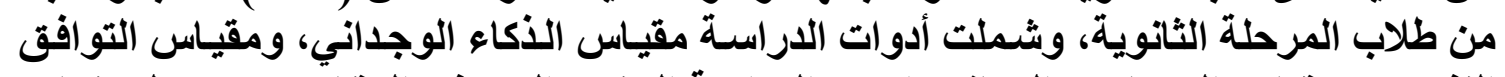

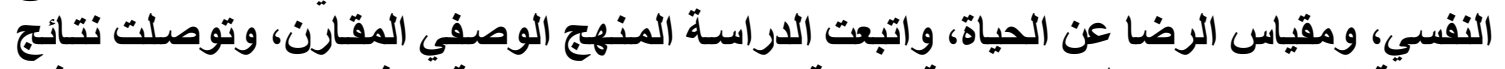

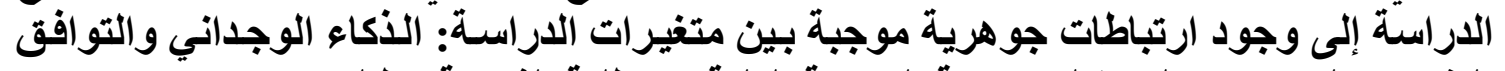

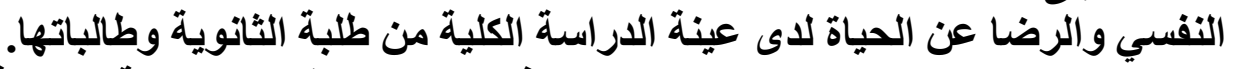

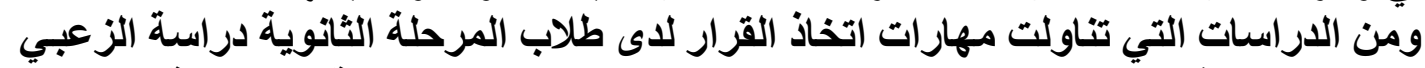

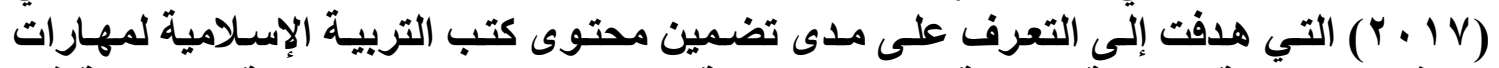

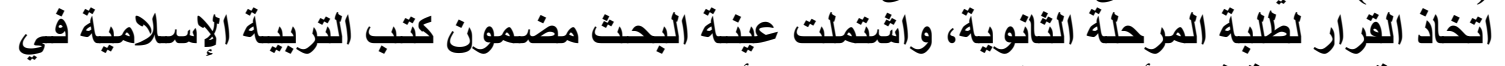

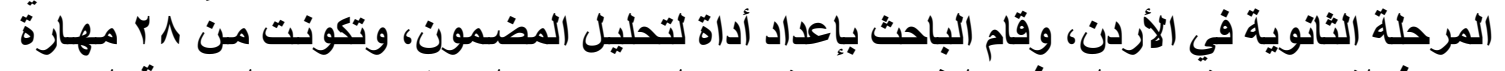

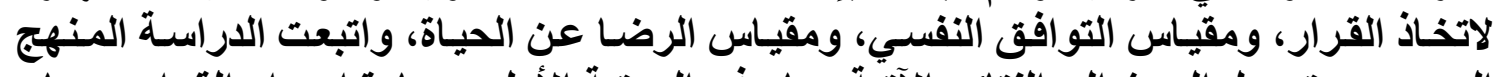

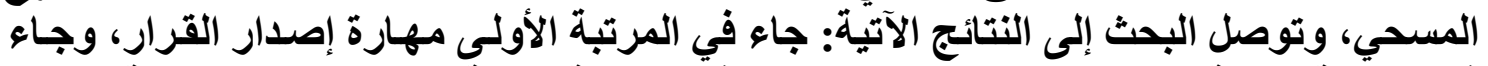

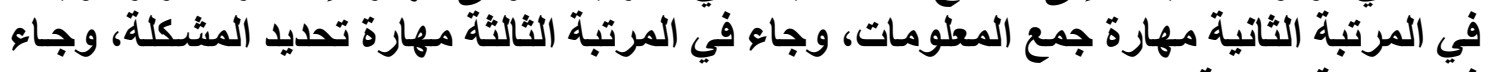

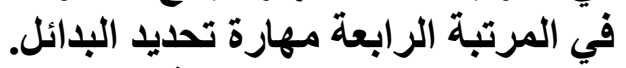

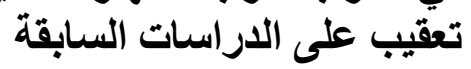

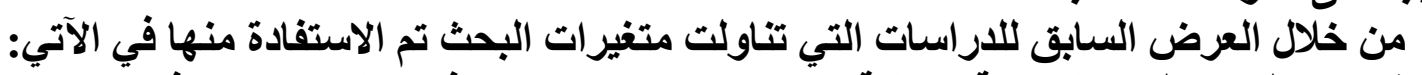

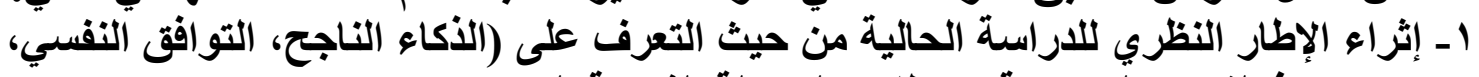

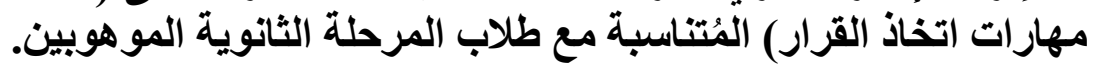


r ـ الاستفادة من الدراسات السابقة في طريقة اختيار منهج الداراسة وتحديد العينة.

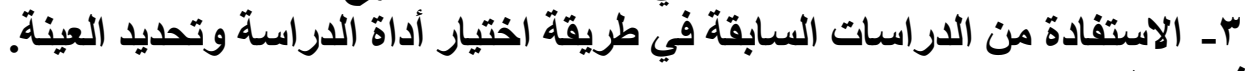
فرض البحث ا - توجد علاقة إرتباطية ذات دلاية إحصائية بين الأكاء الناجح ومهارات اتخاذ القرار لاى

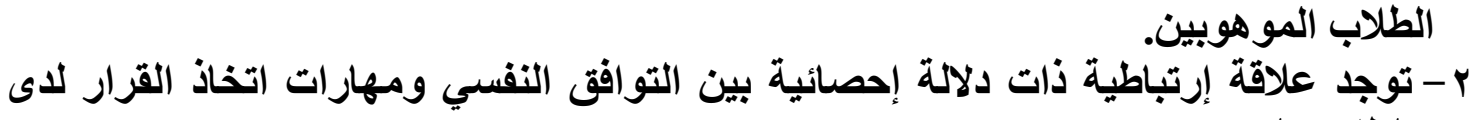
الطلاب الموهوبين.

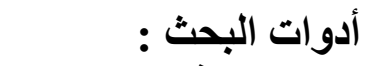
مقياس الأكاء الثثلاثي:

تم تطبيق مقياس الأكاء الناجح (إعداء الباد الباحث).

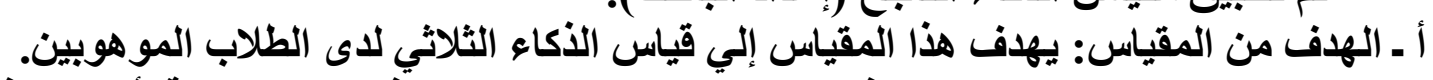

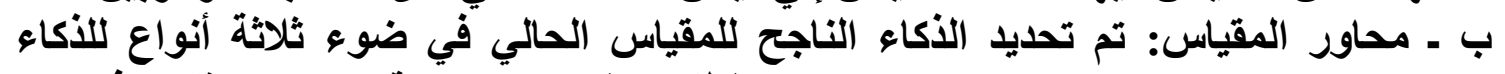

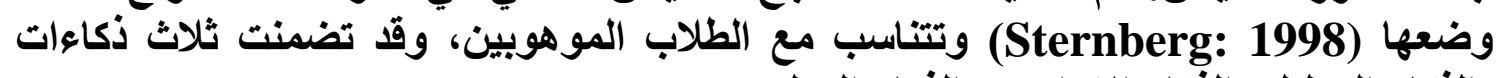
(الأكاء التحليلي-الأكاء الإبداعي - الأكاء العملي).

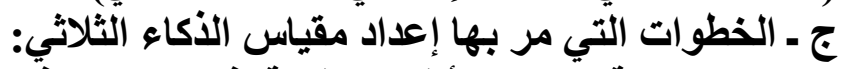

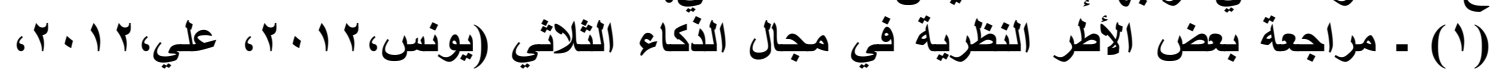
.(Sternberg,2010 (Y) ـ تمث الاستفادة من بعض المقاييس المُعدة للأكاء الثلاثي في إعداد الصورة الأولية لمقياس

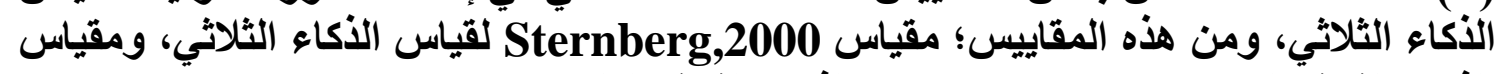

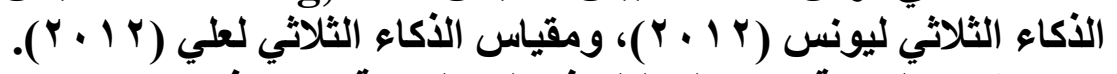

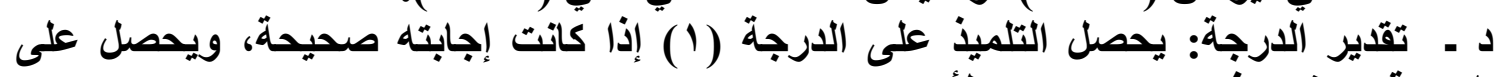

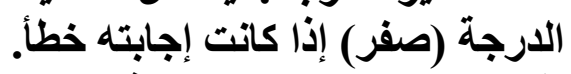

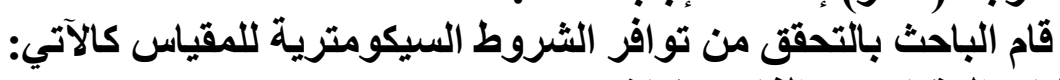

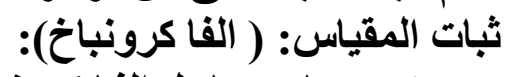

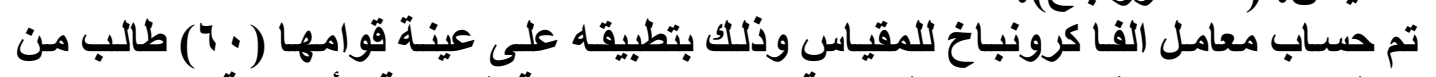

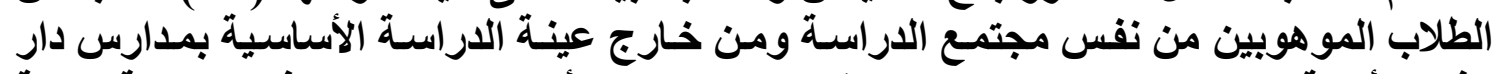

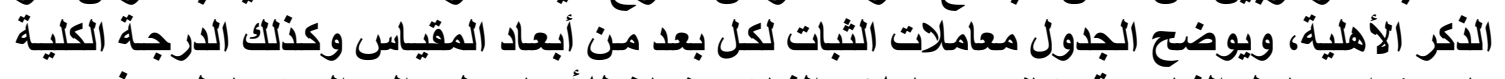

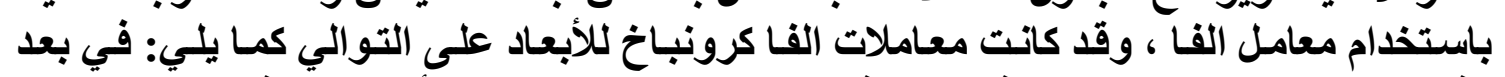

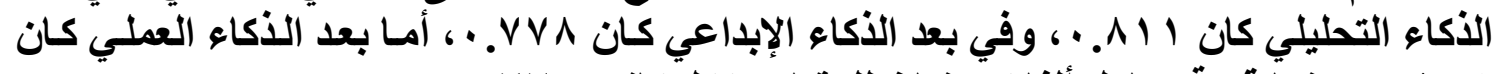

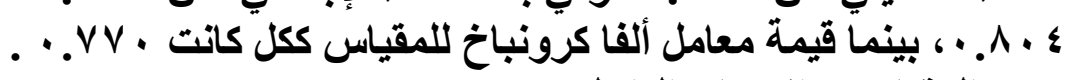
صدق المقياس: (الاتساق الداخلي):

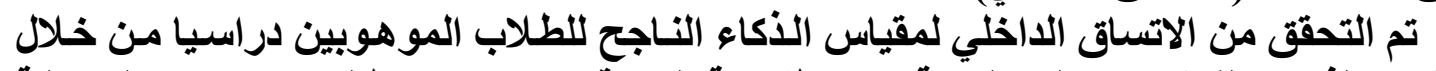

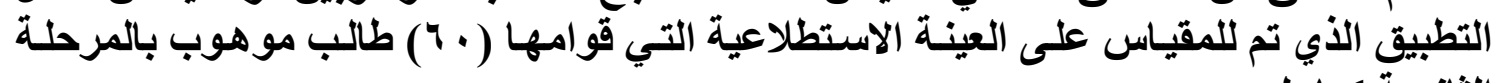

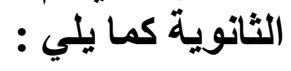


أ) حساب معاملات الارتباط بين مفردات المقياس والدرجة الكلية للأبعاد كل على حده :

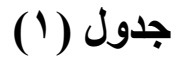

معاملات الارتباط بين مفردات مقياس الأكاء الناجح للطلاب الموهوبين دراسيا

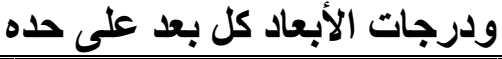

\begin{tabular}{|c|c|c|c|c|c|}
\hline \multicolumn{2}{|c|}{ الأكاء العملي } & \multicolumn{2}{|c|}{ الأكاء الإبداعى } & \multicolumn{2}{|c|}{ الأكاء التحليلي } \\
\hline المفردة بالدرجة ارتباط & المفردة & المفردة بالارجة ارتباطة & المفردة & المفردة بالدرجة ارتباطة & المفردة \\
\hline$* *, \leqslant \wedge \mu$ & ro & $* *, \diamond \wedge V$ & 14 & $* *, 0,7$ & 1 \\
\hline$* *, 0,7$ & Y & $* * .0 .7$ & $1 \varepsilon$ & $* * . . \leqslant 07$ & $r$ \\
\hline$* *, 00 \leqslant$ & $r V$ & $* *, .7, r$ & 10 & $* *, .7, r$ & $r$ \\
\hline$* *, . \leqslant \wedge q$ & rA & $* *, . \leqslant \wedge \mu$ & 17 & $* * . .779$ & $\varepsilon$ \\
\hline$* *, . \leqslant 07$ & rq & $* *, . \leqslant 07$ & IV & $* *, . V, \varepsilon$ & 0 \\
\hline$* *, . \leqslant \mu V$ & r. & $* *, 0,7$ & 11 & $* *, . \vee Y \Lambda$ & 7 \\
\hline$* . . \mu r \mu$ & $\mu_{1}$ & $* *, . \leqslant 07$ & 19 & $* *, . \leqslant 07$ & V \\
\hline ט & $M r$ & $* * . . \wedge \vee Y$ & $r$. & $* *, \ldots 07$ & $\Lambda$ \\
\hline$* *, .7 \leq 1$ & $\mu$ & $* * \cdot .7 \cdot Y$ & Y & $* * . .7 \% 0$ & 9 \\
\hline$* . \quad r \leqslant q$ & $\Gamma \xi$ & $* *, . \vee 0 \varepsilon$ & rr & $* * .00 \leqslant$ & 1. \\
\hline$* * . \vee \vee 0$. & ro & $* * .0 .7$ & $r r$ & $* * .00\}$ & 11 \\
\hline$* *, .7 \leq 0$ & ry & $* * .779$ & $r \varepsilon$ & $* * \ldots \leqslant 07$ & Ir \\
\hline
\end{tabular}

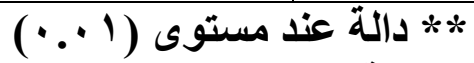

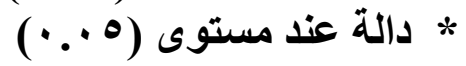

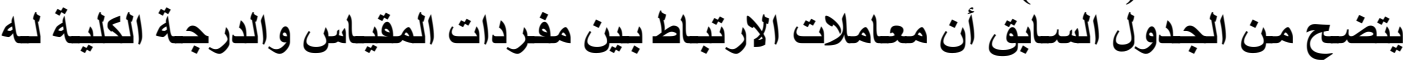

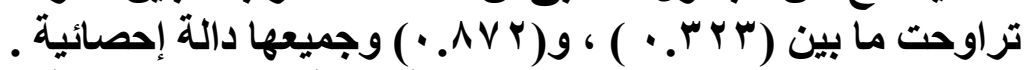

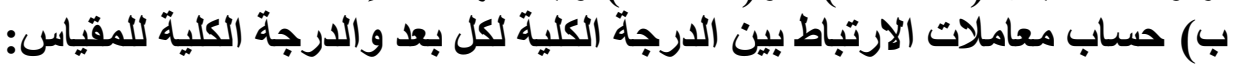

\section{جدول (Y)}

معاملات الارتباط بين الدرجة الكلية لكل بعد من أبعاد مقياس الأكاء الناجح للطلاب الموهوبين

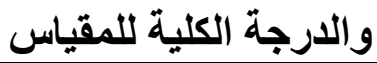

\begin{tabular}{|c|c|}
\hline معامل الارتباط & أبعاد المقياس \\
\hline$* * . . \vee 91$ & الأكاء التحليلي \\
\hline$* *, . \wedge \wedge$. & الأكاء الإبداعي \\
\hline$* * \cdot . \Lambda \cdot V$ & الأكاء العملى \\
\hline
\end{tabular}

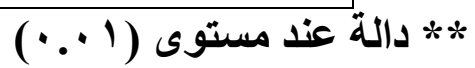

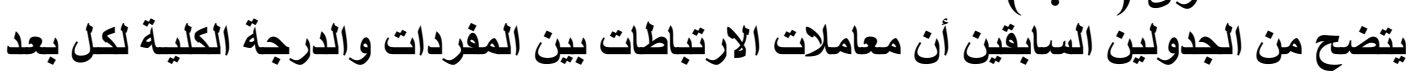

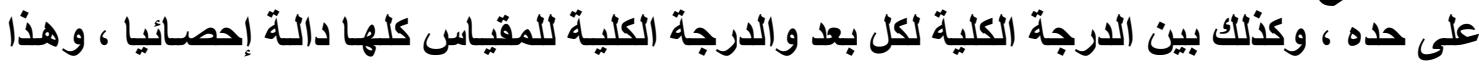
يلدل على ترابط وتماسك المفردات والأبعاد ؛ مما يال على وأن المقلى المقياس يتمتع باتساق داخلي . 


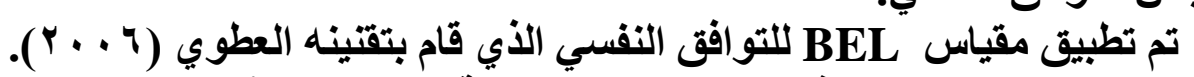

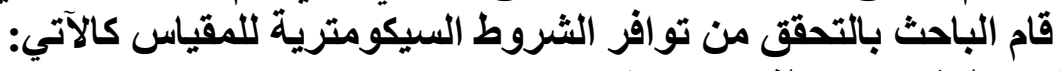

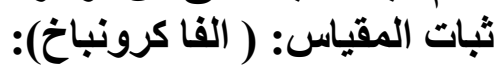

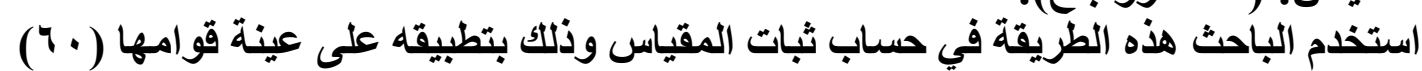

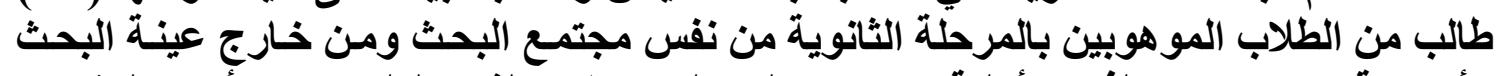

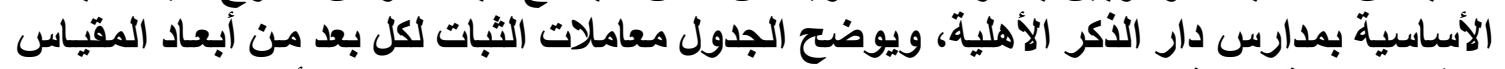

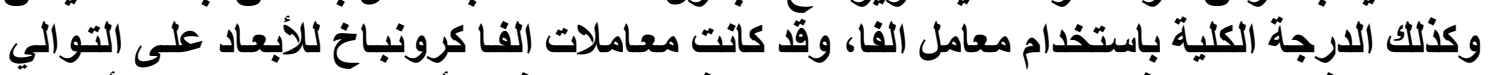

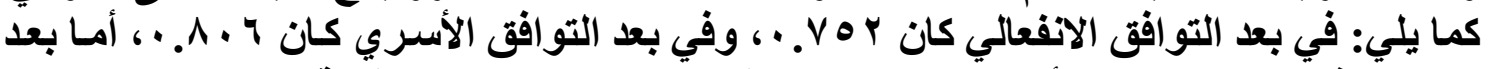

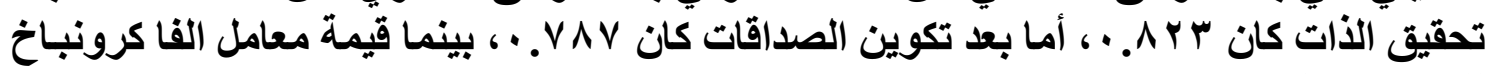

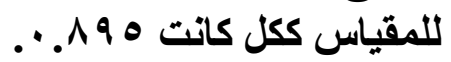

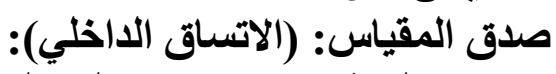

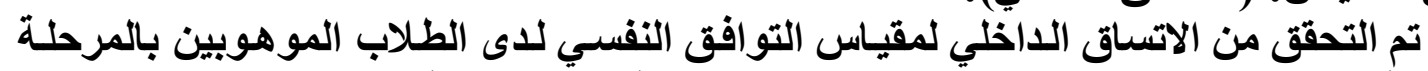

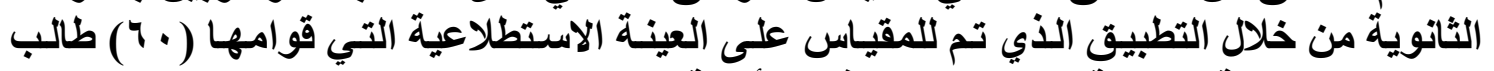

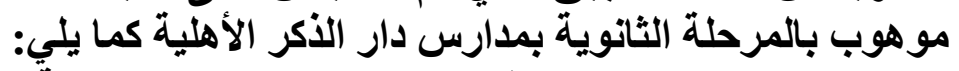

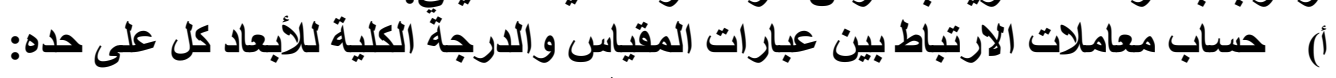

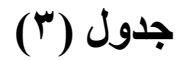

معاملات الارتباط بين عبارات مقياس التوافق النفسي لاى الطلاب المولهوبين بالمرحلة الثانوية

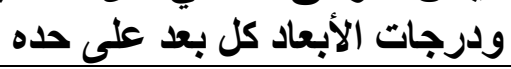

\begin{tabular}{|c|c|c|c|c|c|c|c|}
\hline \multicolumn{2}{|c|}{ تكوين الصداقات } & \multicolumn{2}{|c|}{ تحقيق الذات } & \multicolumn{2}{|c|}{ التوافق الأسري } & \multicolumn{2}{|c|}{ التوافق الانفعالي } \\
\hline الكالعابة العبارة & العبارة & العالعبارة العباطة & العبارة & معامل ارتباط العبارة & العبارة & 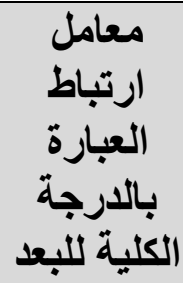 & العبارة \\
\hline$* * . . v+1$ & 9 . & $* * .07$. & 79 & *.rYro & ro & $* * .07 r$ & 1 \\
\hline$* * . .7 \leqslant 0$ & 91 & $* * . .7 \leqslant \Lambda$ & $v$. & $* * . .701$ & ד & $* * . \wedge \ldots$ & $r$ \\
\hline$* * . .7 \ldots$ & $q Y$ & $* * . . \vee \wedge 1$ & VI & $* * . .7 \ldots$ & $r v$ & $* * . .7 \leqslant 0$ & $r$ \\
\hline$* * .074$ & 94 & $* * . . v \cdot 1$ & $V Y$ & $* * . . \leqslant 07$ & rA & 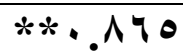 & $\varepsilon$ \\
\hline$* * . .\{07$ & $9 \leqslant$ & $* * . . V \ldots$ & $V \mu$ & $*$. *YO & $r q$ & $* * . \wedge \uparrow 0$ & 0 \\
\hline$* *$. VYO & 90 & $* \cdot . r \leq 1$ & $V \varepsilon$ & $* * . . \neg \wedge r$ & $\varepsilon$. & $* * . . \vee Y \wedge$ & 7 \\
\hline$* * . .7 \leqslant 1$ & 97 & $* * . .7 \leqslant 1$ & Vo & $* * . .707$ & \&1 & $* * . \wedge \uparrow \wedge$ & v \\
\hline$* * . .7 \ldots$ & $9 V$ & $* * . . \vee q$. & $\sqrt{74}$ & $* * . .\{91$ & $\varepsilon r$ & $* * . .7 \varepsilon$. & $\Lambda$ \\
\hline$* * . .70 \leqslant$ & 91 & $* *$ *.VYO & $V V$ & $* * . .7 \ldots$ & $\varepsilon r$ & $* * .0 Y V$ & 9 \\
\hline$* * .7 \leqslant V$ & 99 & $* * . . \wedge Y \Gamma$ & $\vee \wedge$ & $* * . \wedge \varepsilon$ & $\varepsilon \varepsilon$ & $* * . . \leqslant 9 \leqslant$ & 1. \\
\hline$* * . \wedge Y$. & $1 \ldots$ & $* * . . \wedge \cdot 1$ & $\sqrt{9}$ & $* . . T Y A$ & $\leqslant 0$ & $* * .791$ & 11 \\
\hline$* * .0 Y 4$ & $1 \cdot 1$ & $* * . .7 \wedge r$ & A. & $* * . .079$ & $\leqslant 7$ & $* * . v \cdot 1$ & Ir \\
\hline$* * . . T \leqslant Y$ & $1 \cdot r$ & $* * . .7 \leqslant 1$ & $\Lambda 1$ & $* . . r Y q$ & $\varepsilon V$ & $* * . . \$ 97$ & $1 \pi$ \\
\hline
\end{tabular}




\begin{tabular}{|c|c|c|c|c|c|c|c|}
\hline \multicolumn{2}{|c|}{ تكوين الصداقات } & \multicolumn{2}{|c|}{ تحقيق الذات } & \multicolumn{2}{|c|}{ التوافق الأسري } & \multicolumn{2}{|c|}{ التوافق الانفعالي } \\
\hline 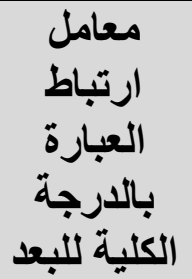 & العبارة & 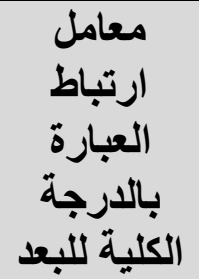 & العبارة & معامل ارتباط العبارة & العبارة & 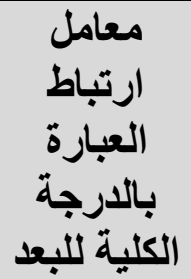 & العبارة \\
\hline$* * . .7 \vee \wedge$ & $1 \cdot r$ & $* * . .7 \leq \Lambda$ & $\overline{A Y}$ & $* *, .0 \leq 1$ & $\varepsilon \wedge$ & $* * . .091$ & $1 \varepsilon$ \\
\hline$* *, . \wedge \ldots$ & $1 \cdot \varepsilon$ & $* * . .7 \leq 1$ & $\Lambda \mu$ & $* * . .7 \mu$. & $\varepsilon q$ & $* *, .7 \wedge V$ & 10 \\
\hline$* *, .70 \leqslant$ & 1.0 & $* * \cdot . \Delta \wedge r$ & $\Lambda \varepsilon$ & $* *, . V, r$ & 0 . & $* *, .7$, & 17 \\
\hline$* * .700$ & 1.7 & $* * . . \leq 99$ & 10 & $* *, . \curlyvee \wedge 0$ & 01 & $* * .09 \varepsilon$ & 18 \\
\hline$* * . .09 \wedge$ & $1 \cdot V$ & $* * \cdot . V \cdot Y$ & $\Lambda 7$ & $* * .0 \leqslant Y$ & $O Y$ & $* * . . \neg \wedge V$ & 11 \\
\hline$* * . . V Y I$ & $1 \cdot 1$ & $* * . .701$ & $\Lambda V$ & $* *, .7 \leq 1$ & $\Delta r$ & $* *, .7 \vee \wedge$ & 19 \\
\hline$* * . . V Y Y$ & 1.9 & $* * . .701$ & $\Lambda \wedge$ & $* * . . Y Y Y$ & O & $* * \cdot . V \cdot 1$ & $r$. \\
\hline$* * . .7 \wedge$ & 11. & $* * \cdot .7 \leq \Lambda$ & 19 & $* * . . \vee \wedge Y$ & 00 & $* * \cdot . v \cdot 1$ & YI \\
\hline$* . . \mu \wedge$ & 111 & & & $* * . .7 \leq 0$ & 07 & $* * . .79 V$ & rY \\
\hline *. rYo & $11 \%$ & & & $* * . .797$ & $O V$ & $* *, . \wedge \ldots$ & $r r$ \\
\hline$* *, . \leq 9 \leq$ & $11 \pi$ & & & *..M. & $\Delta \Lambda$ & $* *, . V Y 0$ & $r \varepsilon$ \\
\hline$* * . \vee \vee 70$ & $11 \varepsilon$ & & & $* * .7$, & 09 & $* * . .791$ & Yo \\
\hline$* *, V, v$ & 110 & & & $* *, . \vee Y \wedge$ & 7. & $* *, . \nearrow \leq Y$ & $r q$ \\
\hline$* *, .7 \leqslant 9$ & 117 & & & $* *, . \Delta Y \wedge$ & 71 & 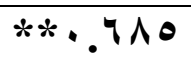 & $r V$ \\
\hline$* * . . \neg \vee \wedge$ & $11 \mathrm{~V}$ & & & $* * .7 \vee 9$ & $7 r$ & $* * . . \vee \neg \wedge$ & $r \wedge$ \\
\hline$* *, 0 \ldots$ & 111 & & & $* *, .7 \vee \wedge$ & $7 \mu$ & $* * .09 \varepsilon$ & rq \\
\hline$* . \mu Y \mu$ & 119 & & & $* *, .0 \leq 9$ & $7 \varepsilon$ & $* *, .7 \vee \wedge$ & $\mu$ \\
\hline$* *, .07 \varepsilon$ & IY. & & & $* *, . \leqslant 90$ & 70 & $* *, . \vee 7 \varepsilon$ & 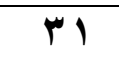 \\
\hline$* *$. $\leqslant 97$ & $|Y|$ & & & *.M & 77 & $* * \bullet . \wedge \neg \wedge$ & $r Y$ \\
\hline & & & & $* *, . \leq 79$ & $7 V$ & $* *, . \wedge \leq 1$ & r \\
\hline & & & & $* * . . \leq 99$ & 71 & $* * . . \neg \wedge V$ & $r \varepsilon$ \\
\hline
\end{tabular}

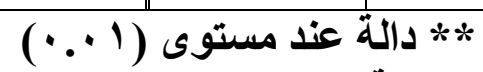

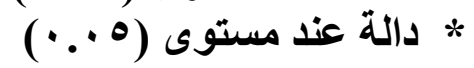

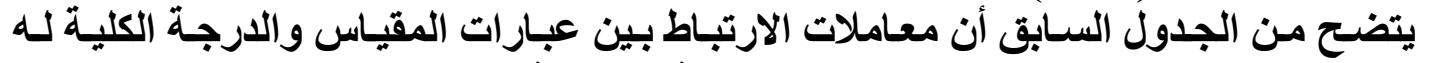

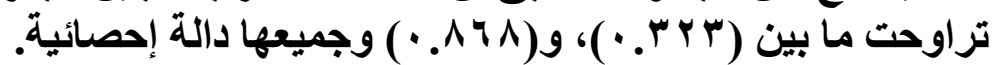
ب) حساب معاملات الارتباط بين الدرجة الثان الكلية لكل بعد والدرجة الكلية للمقياس: 


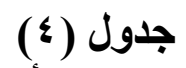

معاملات الارتباط بين الدرجة الكلية لكل بعد من أبعاد مقياس التوافق التفسي لادى الطلاب

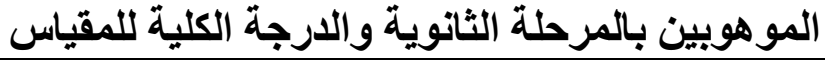

\begin{tabular}{|c|c|}
\hline معامل الارتباط & أبعاد المقياس \\
\hline. .949 & التوافق الانفعالي \\
\hline. .907 & التوافق الأسري \\
\hline$. \wedge \leq 1$ & تحقيق الذات \\
\hline.$\wedge \wedge 7$ & تكوين الصداقات \\
\hline
\end{tabular}

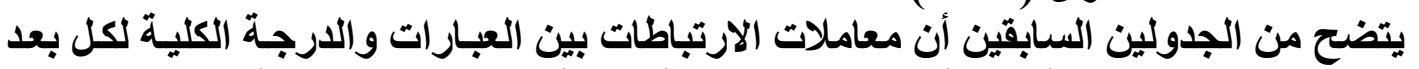

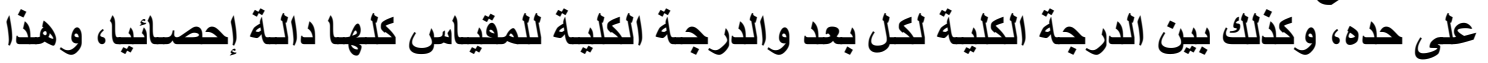

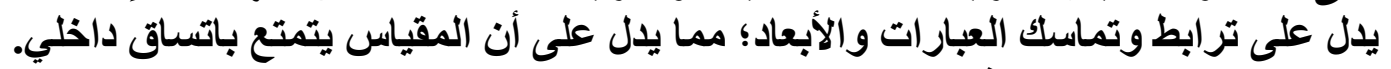
• مقياس مهار ات اتخاذ القرار:

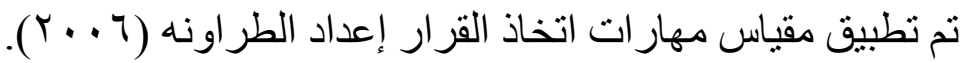
قام الباحث بالتحقق من توافر الشروط السيكومترية للمقياس كالآتي:

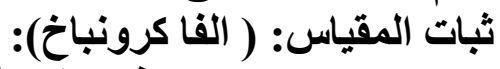

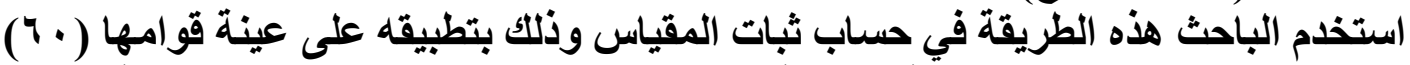

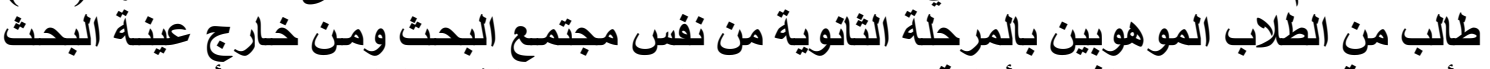

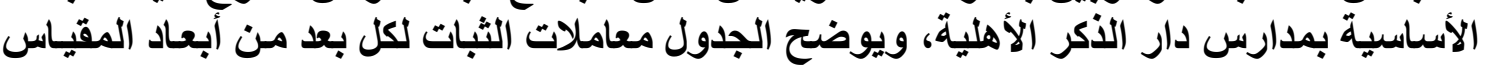

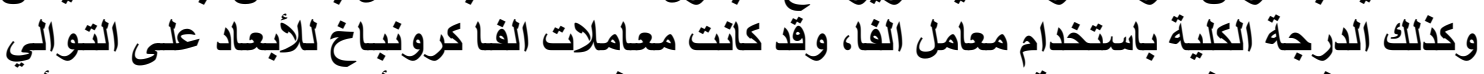

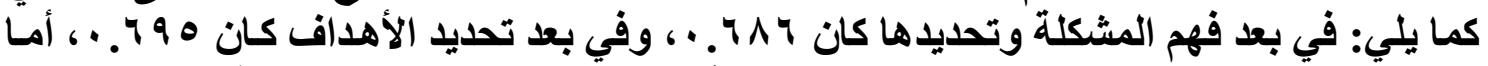

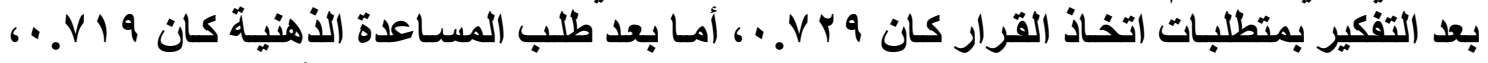

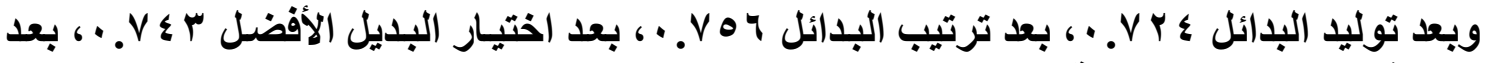

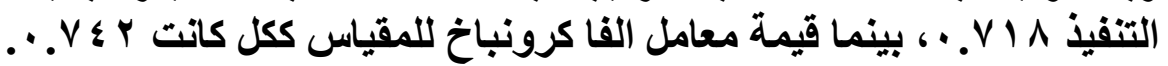

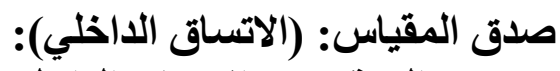

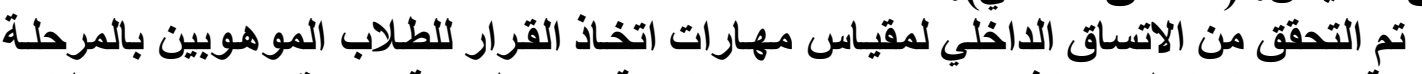

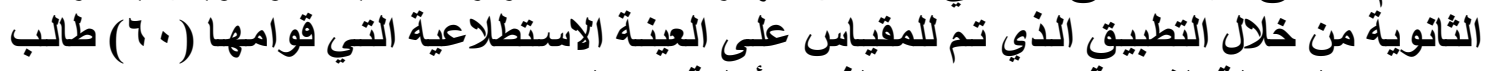

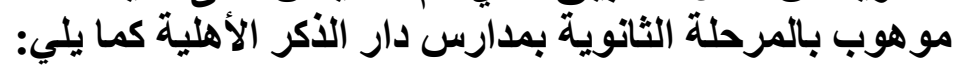

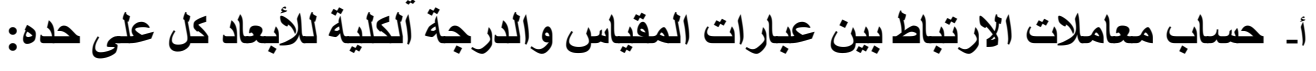




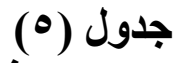

معاملات الارتباط بين عبارات مقياس مهارات اتخاذ القرار لدى الطلاب الموهوبين بالمرحلة

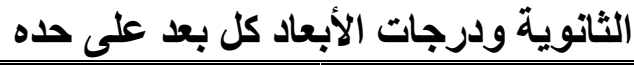

\begin{tabular}{|c|c|c|c|c|c|c|c|}
\hline \multicolumn{2}{|c|}{ طلب المساعدة } & \multicolumn{2}{|c|}{ اتخفير بمتطلبات القرار } & \multicolumn{2}{|c|}{ تحديد الأهداف } & \multicolumn{2}{|c|}{ فهم المشكلة: } \\
\hline 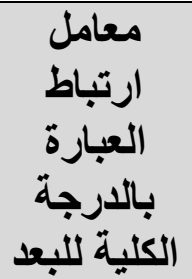 & العبارة & معامل ارتباط العبارة & العبارة & معامل ارتباط العبارة & العبارة & 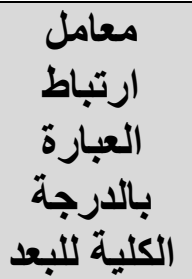 & العبارة \\
\hline$* *, \leqslant 0$. & Ir & $* *, . V \leq 1$ & 0 & $* * . . V Y Y$ & r & $* * . . \sum \vee \wedge$ & 1 \\
\hline$* * . .77 V$ & ir & $* * . \wedge \varepsilon$. & IV & $* * . .7$. & $\varepsilon$ & $* * . . \leqslant 99$ & $\mu$ \\
\hline$* * . . \neg \wedge \mu$ & 19 & $* * . . \vee Y q$ & 11 & $* * . . V Y \mu$ & 19 & $* * . . \leqslant 70$ & $1 \varepsilon$ \\
\hline$* * . V Y r$ & rq & $* *, . V Y$. & rq & $* * .071$ & $r \varepsilon$ & $* * . V Y 0$ & 10 \\
\hline$* * . \wedge Y 1$ & $r$. & $* * .7 \% 0$ & $\mu v$ & $* * . . \leq 91$ & ro & $* * \cdot . \wedge Y M$ & rr \\
\hline$* * . \wedge r q$ & $\mu \wedge$ & $* * .71$ & $0 \leq$ & $* * . .711$ & Or & $* * . \wedge \mu \Delta$ & $r r$ \\
\hline$* * . . V \cdot$. & $r q$ & $* * . .7 \leq 9$ & 09 & $* * . . \Delta \mu r$ & $\Delta r$ & $* * . V Y 0$ & 01 \\
\hline \multicolumn{2}{|c|}{ التنفيذ } & \multicolumn{2}{|c|}{ اختيار البديل الأفضل } & \multicolumn{2}{|c|}{ ترتيب البدائل } & \multicolumn{2}{|c|}{ توليد البدائل } \\
\hline$* * . .719$ & $\Lambda$ & $* * . . \vee q Y$. & V & $* * . . \leqslant 91$ & 7 & $* * \cdot . V \cdot 7$ & $r \cdot$ \\
\hline$* * . .741$ & 9 & $* * . . V 1 \varepsilon$ & $r \leq$ & $* * \cdot . V \cdot 7$ & 1. & $* * .019$ & YI \\
\hline$* * . .749$ & 11 & $* * . .7 r \mu$ & ro & $* *, . V \vee Y$ & $r r$ & $* * . .79 \leq$ & $M$ \\
\hline$* * \cdot . \wedge \ldots$ & YY & $* * . . \wedge 1 Y$ & $\varepsilon Y$ & $* * . . \wedge \mu$. & $r M$ & $* * \cdot . \wedge r q$ & $\varepsilon$. \\
\hline$* * . .0 \wedge 9$ & $r V$ & $* * . . \vee \wedge \mu$ & $\varepsilon r$ & $* * . .7 \% 1$ & $r \wedge$ & $* * . V 11$ & $\& 1$ \\
\hline$* * . .7 V V$ & $\varepsilon \varepsilon$ & $* * . .7 \wedge \Lambda$ & $\varepsilon \Lambda$ & $* *, . \vee 10$ & $\varepsilon V$ & $* * . .797$ & $\leqslant 0$ \\
\hline$* * . .791$ & 0. & $* * . .7 \wedge \Lambda$ & 00 & $* *, . V \leq 1$ & $\varepsilon 9$ & $* * . V q Y$ & 27 \\
\hline
\end{tabular}

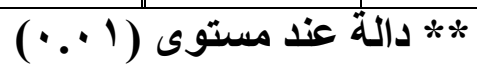

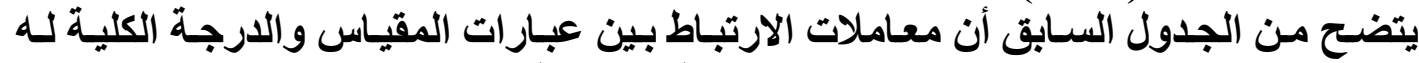

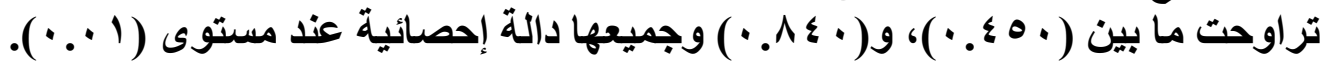

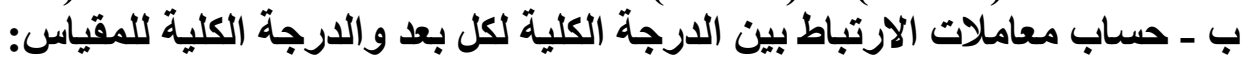

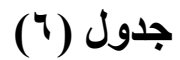

معاملات الارتباط بين الدرجة الكلية لكل بعد من أبعاد مقياس مهارات اتخاذ القرار لاى الطلاب

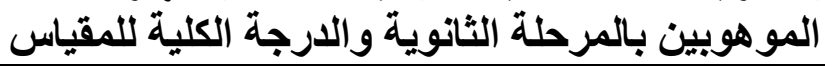

\begin{tabular}{|c|c|}
\hline معامل الارتباط & أبعاد المقياس \\
\hline$. V 1 \leq$ & فهم المشكلة وتحديلها \\
\hline .079 & تحديد الأهداف \\
\hline$\because \wedge 4$ & التفكير بمتطلبات اتخاذ القرار \\
\hline.$\wedge 91$ & طلب المساعدة الذهنية \\
\hline
\end{tabular}




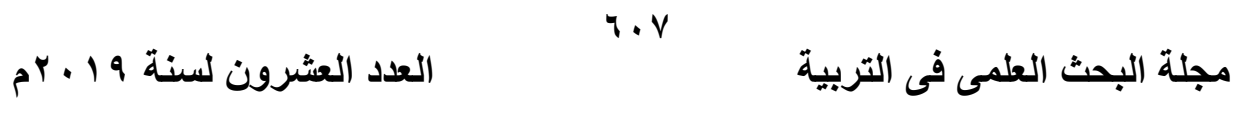

\begin{tabular}{|c|c|}
\hline$\because \vee \wedge$. & توليد البدائل \\
\hline$\cdot . \wedge \cdot 7$ & ترتيب البدائل \\
\hline .974 & اختيار البديل الأفضل \\
\hline$\because V 94$ & التنقيذ \\
\hline
\end{tabular}

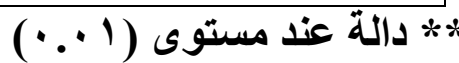

يتضح من الجدولين السابقين أن معاملات الارتباطات بين العبار ات والدارجة الكليـة لكل بعد

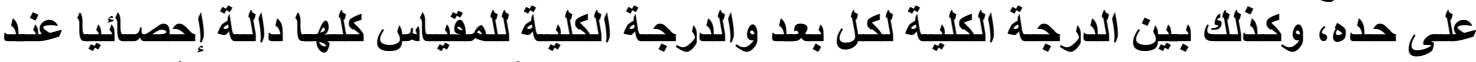

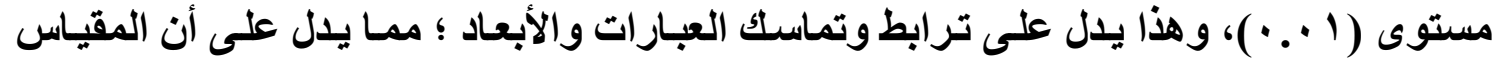
يتمتع باتساق داخلي. عينة الدر استة بالأساسية داخية

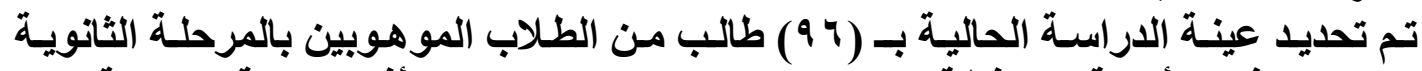

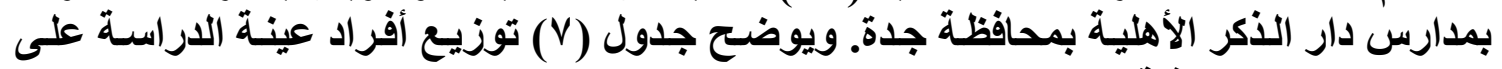
متغير اتها الديموغر دارية.

\section{(V) جدول}

توزيع أفر اد عينة الدراسة وفقا للمتغيرات الايموغرافية

\begin{tabular}{|c|c|}
\hline عدد الطلاب الموهوبين & الصف \\
\hline$\leqslant \varepsilon$ & الأول الثانوي \\
\hline M & الثاني الثانوي \\
\hline YI & الثالث الثانوي \\
\hline 97 & المجموع \\
\hline
\end{tabular}

مناقشة أسئلة الدراسة

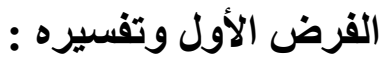

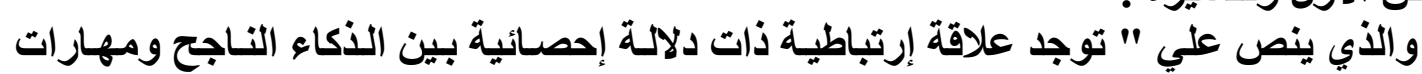

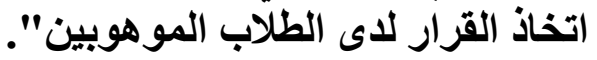

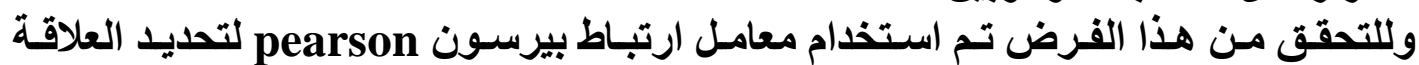

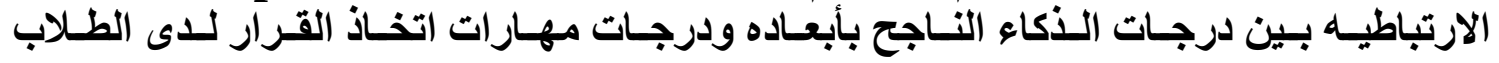
جدول (^) : (^)

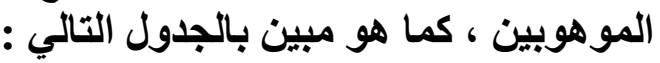

دراسة العلاقة الارتباطية بين مقياس الأكاء الناجح بأبعاده ومقياس مهارات اتخاذ القرار عينة البحث ن= 9

\begin{tabular}{|c|c|c|c|c|c|}
\hline \multicolumn{4}{|c|}{ أبعاد مقياس الأكاء الناجح } & \multirow{2}{*}{ الارتباط } & \multirow[b]{2}{*}{ مهارات اتخاذ القرار } \\
\hline ككل المقياس & ذكاء عملي & ذكاء إبداعي & ذكاء تحليلي & & \\
\hline$* * \cdot .7 \cdot \varepsilon$ & $* * .7 \%$ & $* * \cdot . Y ૫ \varepsilon$ & $* * \cdot .0 Y \varepsilon$ & $J$ & \multirow{2}{*}{ فهم المشكلة وتحديدها } \\
\hline دالة & دالة & دالة & دالة & الدلالة & \\
\hline$* * . . V Y Y$ & $* * . . V I Y$ & $* * . . \% q$. & $* * . .70 \mathrm{~V}$ & J & \multirow{2}{*}{ تحديد الهـف أو الأهداف } \\
\hline دالة & دالة & دالة & دالة & الدلالة & \\
\hline
\end{tabular}




\begin{tabular}{|c|c|c|c|c|c|}
\hline \multicolumn{4}{|c|}{ أبعاد مقياس الأكاء الناجح } & \multirow{2}{*}{ الارتباط } & \multirow[b]{2}{*}{ مهار ات اتخاذ القرار } \\
\hline ككيل المقاس & ذكاء عملي & ذكاء إبداعي & ذكاء تحليلي & & \\
\hline$* * . . \vee 9 \wedge$ & $* *$ *.V7r & $* * . .0 \vee 1$ & $* * . .7 \mu \varepsilon$ & J & \multirow{2}{*}{ التفكير بمتطلبات اتخاذ القرار } \\
\hline دالة & دالة & دالة & دالة & الالاكة & \\
\hline$* * ., Y 10$ &. .11. & 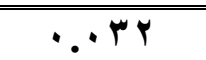 & $* * . . r q \mu$ & J & \multirow{2}{*}{ طلب المساعدة الذهنية } \\
\hline دالة & غير دالة & غير دالة & دالة & الدلاكة & \\
\hline$* * .09$. & $* * * . \Delta \wedge \neg$ & $* *, . \leqslant \vee \wedge$ & $* * \cdot . \varepsilon \cdot 9$ & J & \multirow{2}{*}{ توليل البدائل } \\
\hline دالة & دالة & دالة & دالة & الالاكة & \\
\hline$* * \cdot . \vee \otimes 0$ & $* * . . \mathrm{VV}$ & ***.Yr. & $* * \cdot . V \varepsilon$. & J & \multirow{2}{*}{ ترتيب البدائل والمفاضلة } \\
\hline دالة & دالة & دالة & دالة & الالالة & \\
\hline$* *, . \leqslant 19$ & $* * . . \% 99$ & $* *, . \leqslant 19$ & $* * \cdot$ *Y & J & \multirow{2}{*}{ اختيار البديل الأفضل } \\
\hline دالة & دالة & دالة & دالة & الالالة & \\
\hline$* * . \wedge 70$ & $* * \cdot . \wedge 79$ & $* * . . \leqslant 11$ & $* * \cdot . \vee 70$ & J & \multirow{2}{*}{ التنفيذ } \\
\hline دالة & دالة & دالة & دالة & الدلالة & \\
\hline$* * \cdot . \wedge \varepsilon \varepsilon$ & 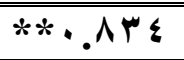 & $* * \cdot . \leqslant \leqslant V$ & $* * \cdot . \vee \mu \wedge$ & 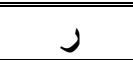 & \multirow{2}{*}{ المقياس ككل } \\
\hline دالة & دالة & دالة & دالة & الالاكة & \\
\hline
\end{tabular}

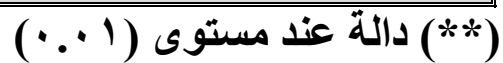

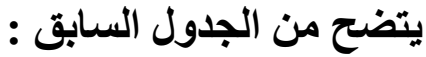

وجود علاقة ارتباطيه طردية موجبة ذات التات دلانة إحصائية بين درجات الطلاب الموهوبين في

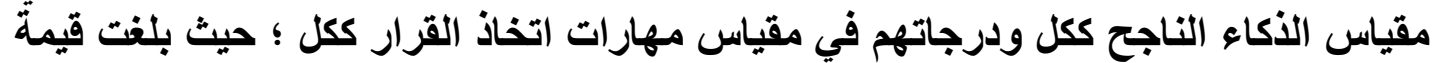

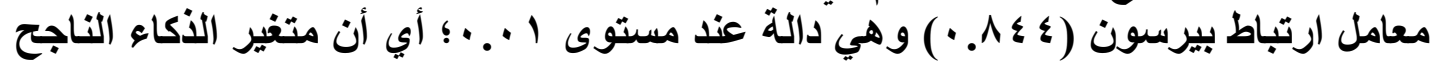

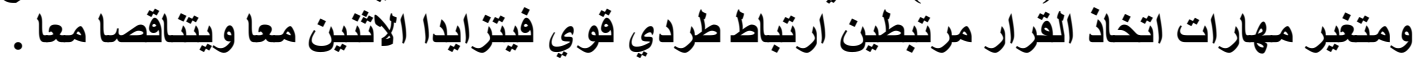

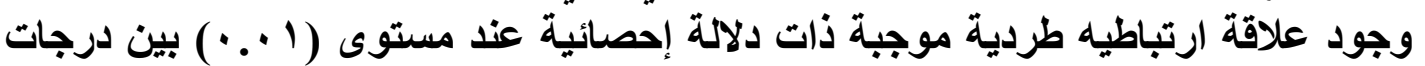

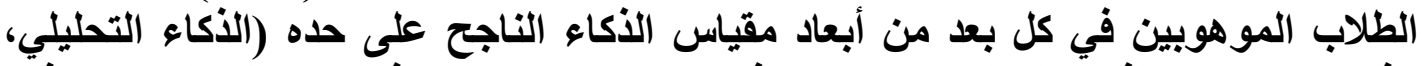

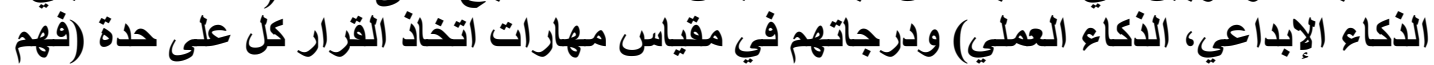

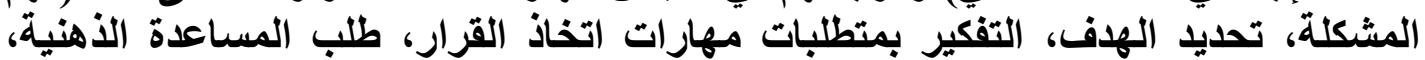

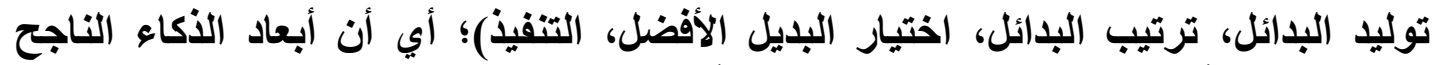

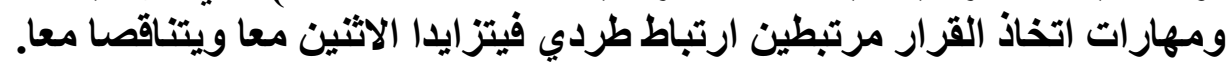

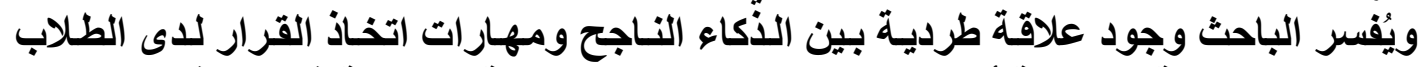

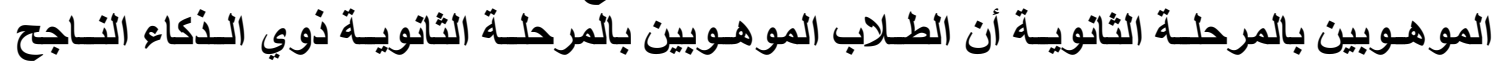

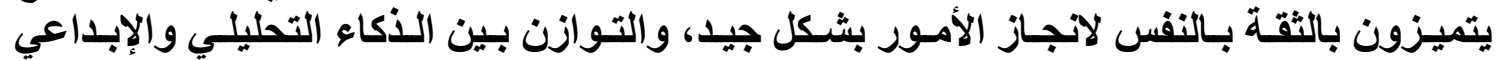

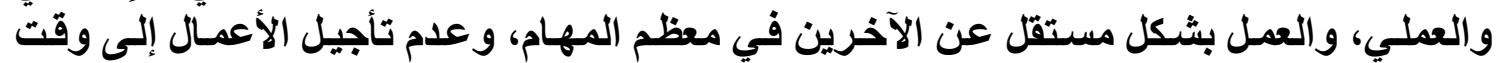

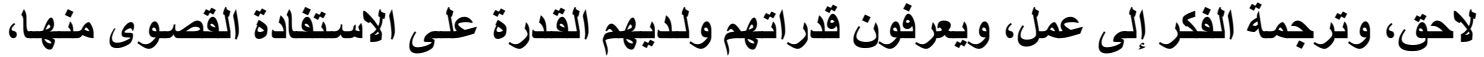

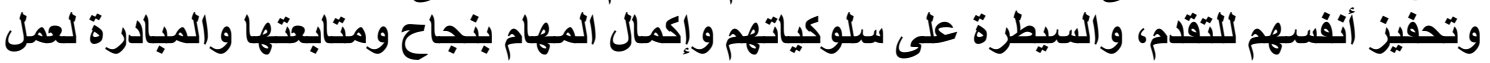

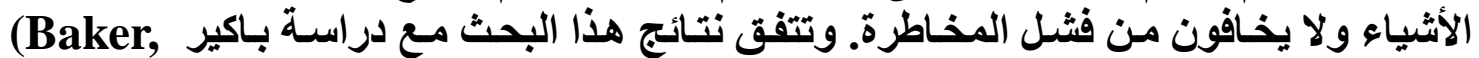

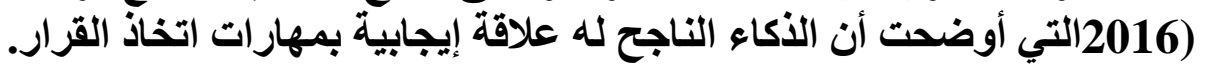
الفرض الثاني وتفسيره:

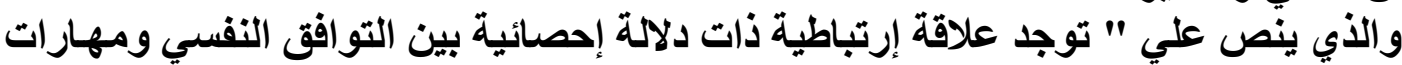

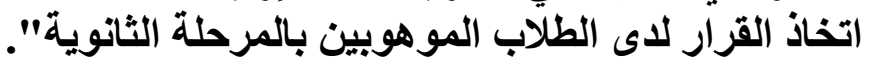




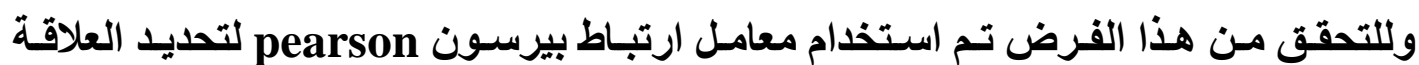

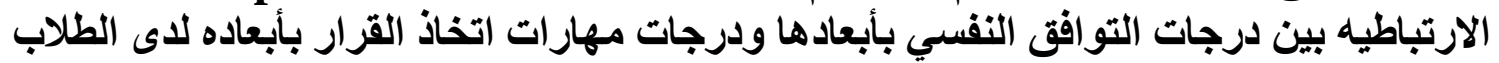

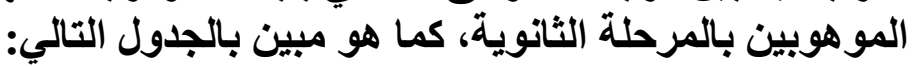

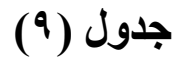

دراسة العلاقة الارتباطية بين مقياس التوافق النفسي بأبعاده ومقياس مهارات اتخاذ القرار بأبعاد

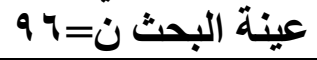

\begin{tabular}{|c|c|c|c|c|c|c|}
\hline \multicolumn{5}{|c|}{ أبعاد التوافق النفسي } & \multirow[b]{2}{*}{ الارتباط معامل } & \multirow[b]{2}{*}{ أبعاد اتخاذ القرار } \\
\hline كکن المقاس & الصداقات تكوين & تحقيت & الأسري & الانفعالي افتي & & \\
\hline$* * * .7 Y V$ & $* * .07 \mathrm{~V}$ & $* * .011$ & $* * .091$ & $* * .791$ & $J$ & فهم المشكلة \\
\hline دالة & دالة & دالة & دالة & دالة & الالاكة & وتحديدها \\
\hline$* *, . V, 0$ & $* *, . \vee \diamond \Lambda$ & $* * . . \% q$. & $* * . .779$ & $* * .70$. & $J$ & تحديد الكهف أو \\
\hline دالة & دالة & دالة & دالة & دالة & الالالة & الأهداف \\
\hline$* * . \wedge \Psi \varepsilon$ & $* * \cdot . \wedge \mu V$ & $* * . . \Delta V Y$ & $* * . \wedge Y I$ & $* *, V \leq 0$ & J & التفكير بمتطلبات \\
\hline دالة & دالة & دالة & دالة & دالة & الدلالة & اتخاذ القرار \\
\hline$* *, \ldots \Delta \mu$ & $* * \cdot \mu \mu$. & $* *, . \varepsilon, \mu$ & $* * . . \leqslant 7 \mu$ & $* * \cdot .7 \cdot V$ & $\jmath$ & طلب المساعدة \\
\hline دالة & دالة & دالة & دالة & دالة & الدلالة & الأهنية \\
\hline$* * . .797$ & $* *, . \vee 07$ & $* *, .4 q 1$ & $* * \cdot . V \cdot q$ & $* * .0,0$ & $\jmath$ & \\
\hline دالة & دالة & دالة & دالة & دالة & الالاكة & \\
\hline$* * \cdot . \wedge \leq \mu$ & $* * \cdot . \wedge \leq \wedge$ & $* * . .099$ & $* * . \vee \wedge 1$ & $* * . \wedge \varepsilon$. & J & ترتيب البدائل \\
\hline دالة & دالة & دالة & دالة & دالة & الالالة & والمفاضلة \\
\hline$* * . .0 \vee 7$ & $* * \cdot .7 \leq 7$ & $* *, . Y \wedge \mu$ & $* * . .7 r \mu$ & $* * . \mu \mid \Lambda$ & 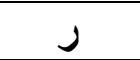 & \\
\hline دالة & دالة & دالة & دالة & دالة & الالالة & | \\
\hline$* * .9 .9$ & $* * .90$. & $* * .71 Y$ & $* * \cdot . \wedge \varepsilon V$ & $* * . \wedge 10$ & $J$ & \\
\hline دالة & دالة & دالة & دالة & دالة & الالالة & \\
\hline$* * .9 Y 0$ & $* * \cdot .9 \leq Y$ & $* * * .7 Y \varepsilon$ & $* * . \wedge q r$ & $* *, . \wedge \leq V$ & $\jmath$ & \\
\hline دالة & دالة & دالة & دالة & دالة & الالالة & \\
\hline
\end{tabular}

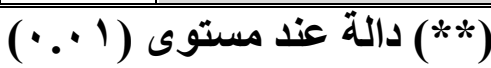

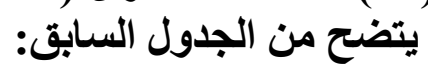

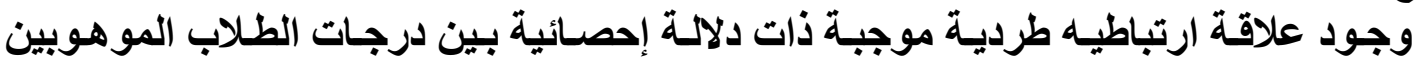

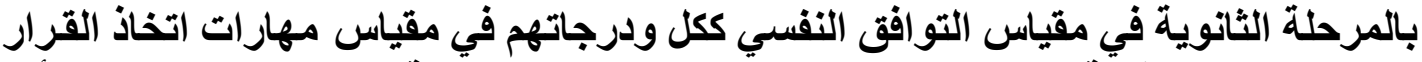

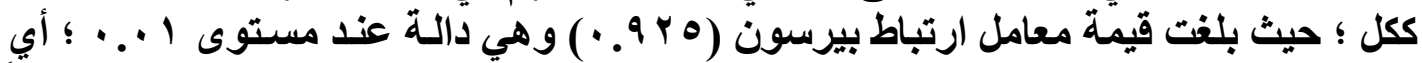

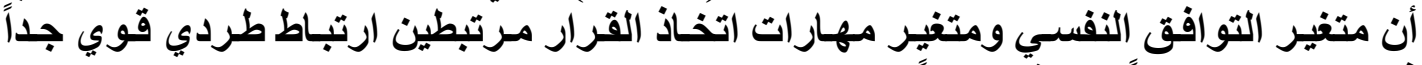
فيتزايدا الاثثين معاً ويتناقصا معاً.

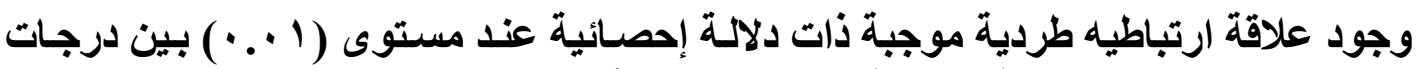

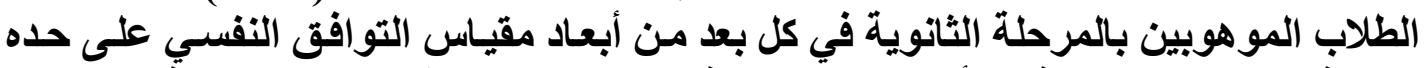

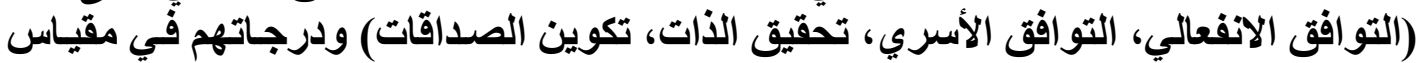

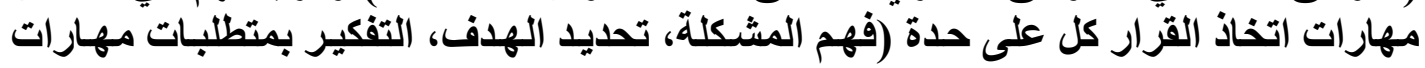




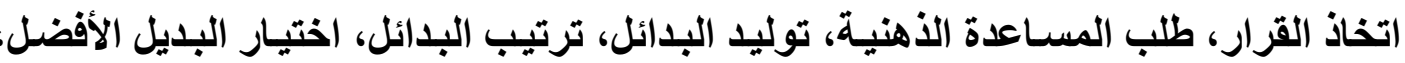

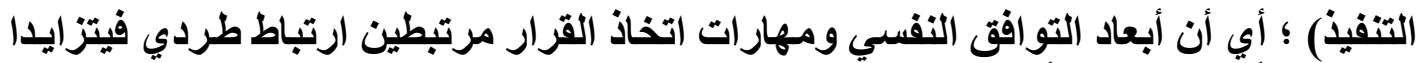
الاثنين معاً ويتناقصا معاً.

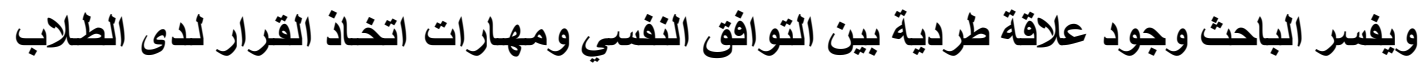

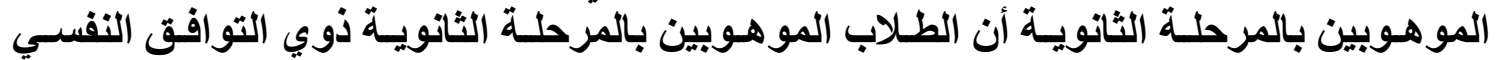

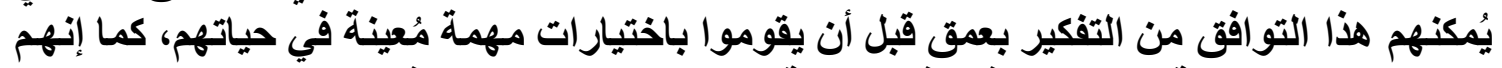

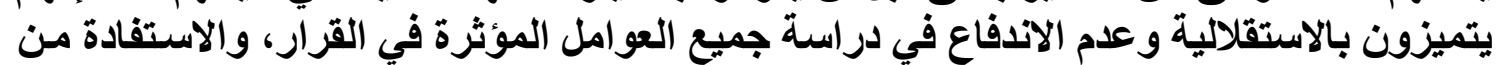

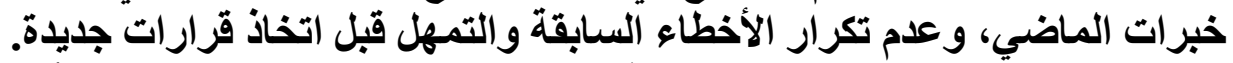

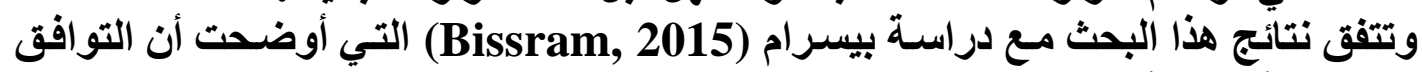

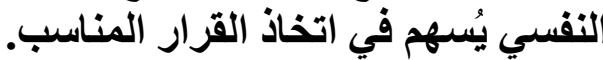

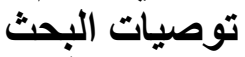

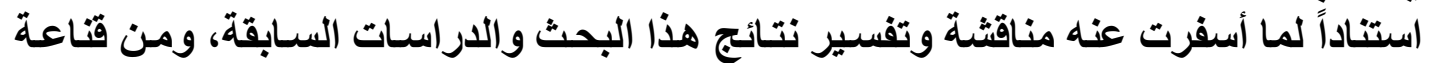

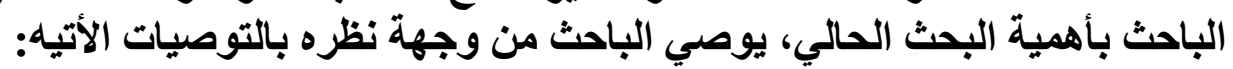

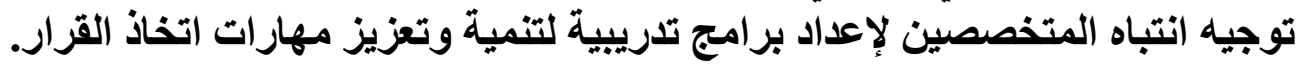

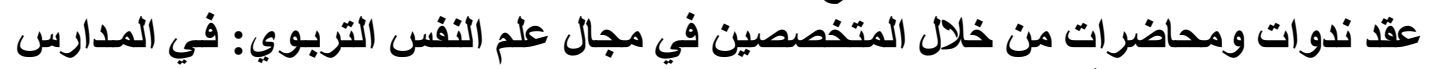
والجامعات، تثناول الأكاء وماهرات الناجح.

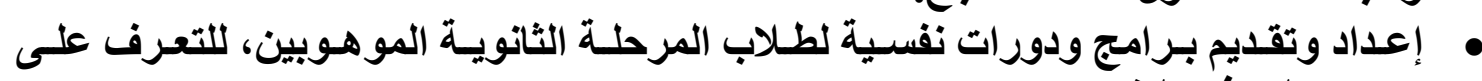
مصادر التوافق التفسي.

\section{المراجا: المراجع

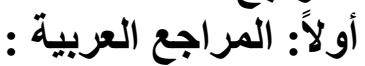

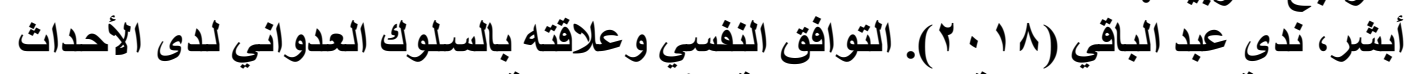

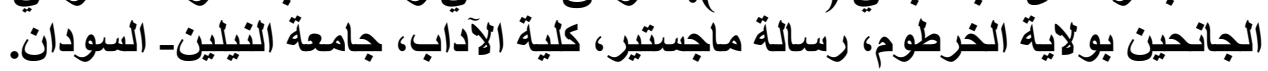

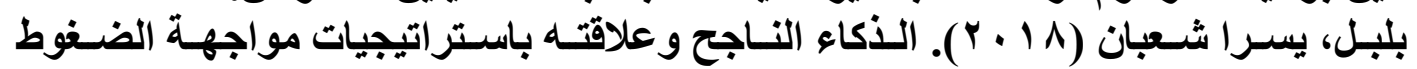

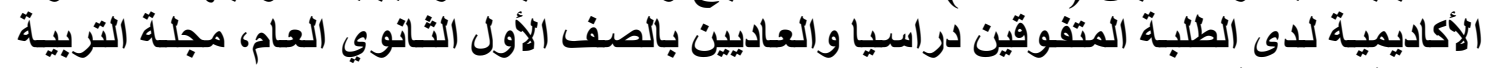

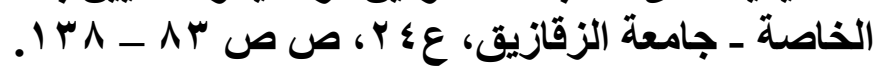

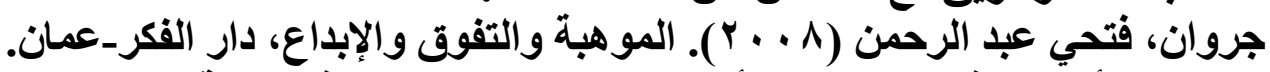

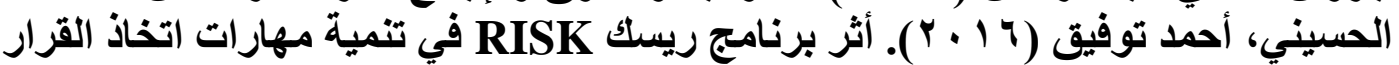

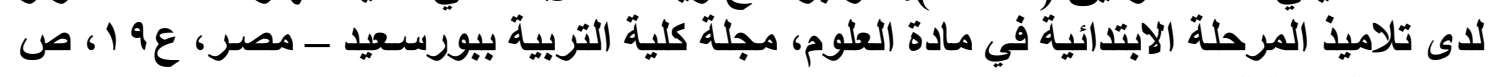

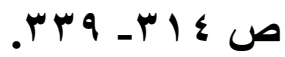

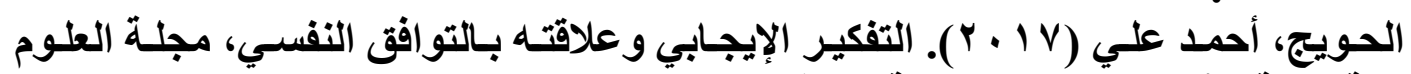

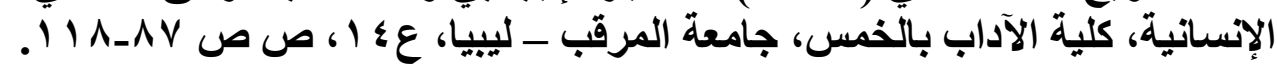

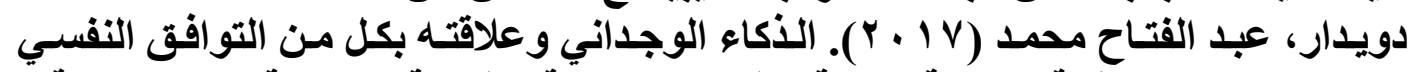

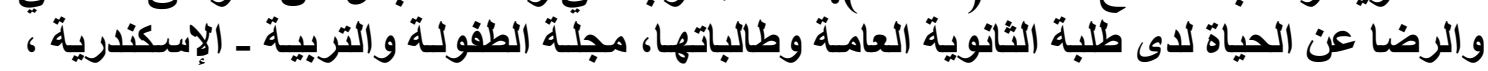

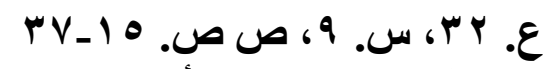

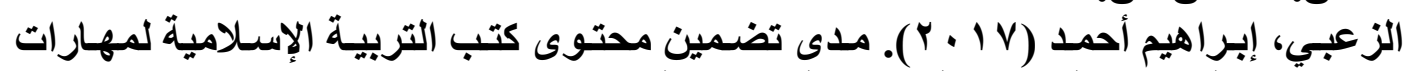

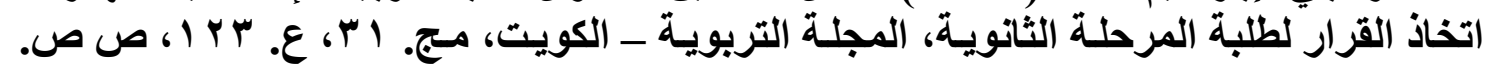




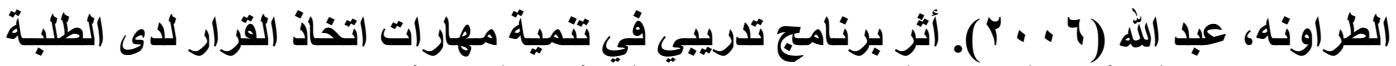

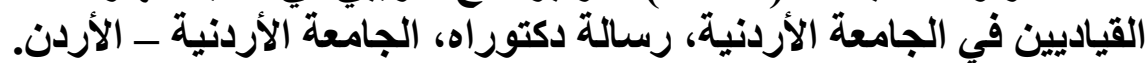

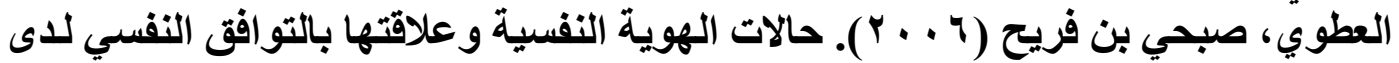

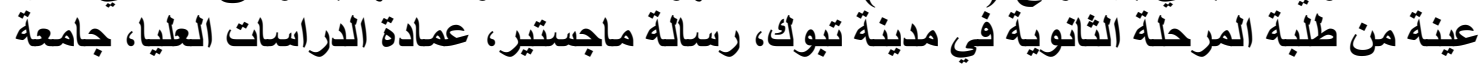

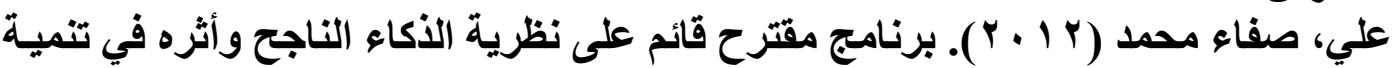

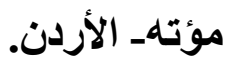

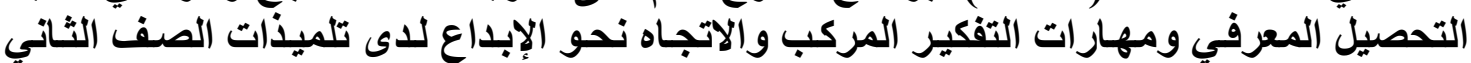

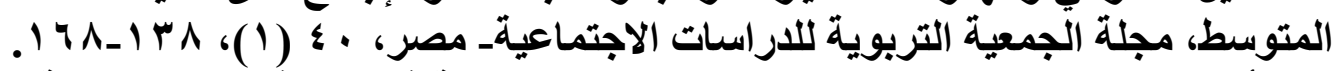

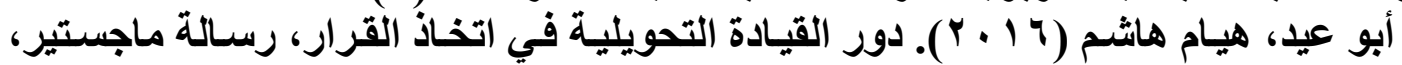
كلية الأعمال، جامعة عمان العربية، الأردن.

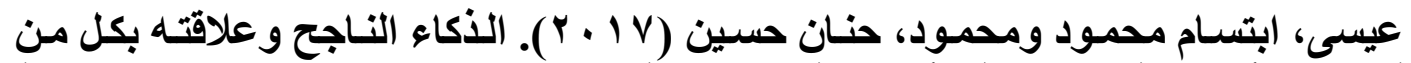

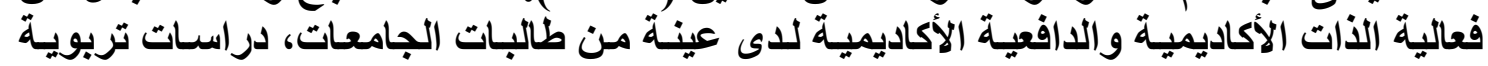

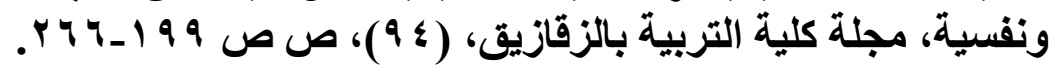

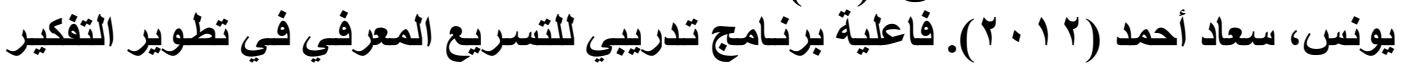

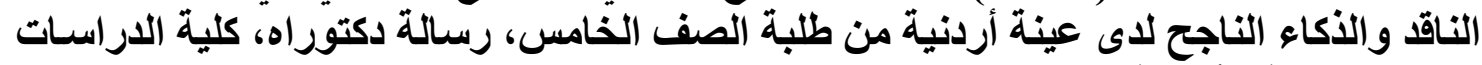

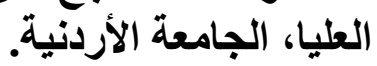

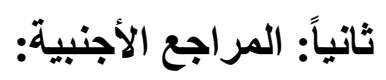

Baker, M (2016). "The Effects of Kolb's Experiential Learning Model on Successful Intelligence in Secondary Agriculture Students", Journal of Agricultural Education, v57 n3 p129-144.

Bissram, J (2015). "The effects of acculturative factors and academic self-efficacy on international students' psychological adjustment", Doctoral Dissertation , State University of New York at Albany.

Ersoy, E (2016). "Psychometric Properties of the Gifted Students' Coping with Anger and Decision Making Skills Scale", Journal of Education and Practice, v7 n15 p121-128.

(2011). "Acculturation and psychological adjustment Goforth, A among Arab American adolescents", Doctoral Dissertation, Michigan State University.

Palos, R (2013). "Teaching for Successful Intelligence

Questionnaire (TSI-Q) - a new instrument developed for assessing teaching style", Journal of Educational Sciences \& Psychology, Vol. 3 .Issue 1, p159-178

(2015). "Psychometric Evaluation of the Brief Peterson, A Adjustment Scale-6 (BASE-6): A New Measure of General Psychological Adjustment", Doctoral Dissertation , University of Washington 
Simmons, J (2017). "The Development and Validation of a Novice Nurse Decision-Making Skills Education Curriculum", Doctoral Dissertation, Walden University. Sternberg, R (2010 ) . "Ssessment Of Gifted Students For Identification Purposes: New Techniques For A New Millennium", Learning And Individual Differences, 4 :327-336. Sternberg, R (2012): " A Model For College And University Admissions" Educational Psychologist, 47 :30-41. Sternberg, R. (2000). Teaching For Successful Intelligence. Arlington Heights, Il: Skylight.

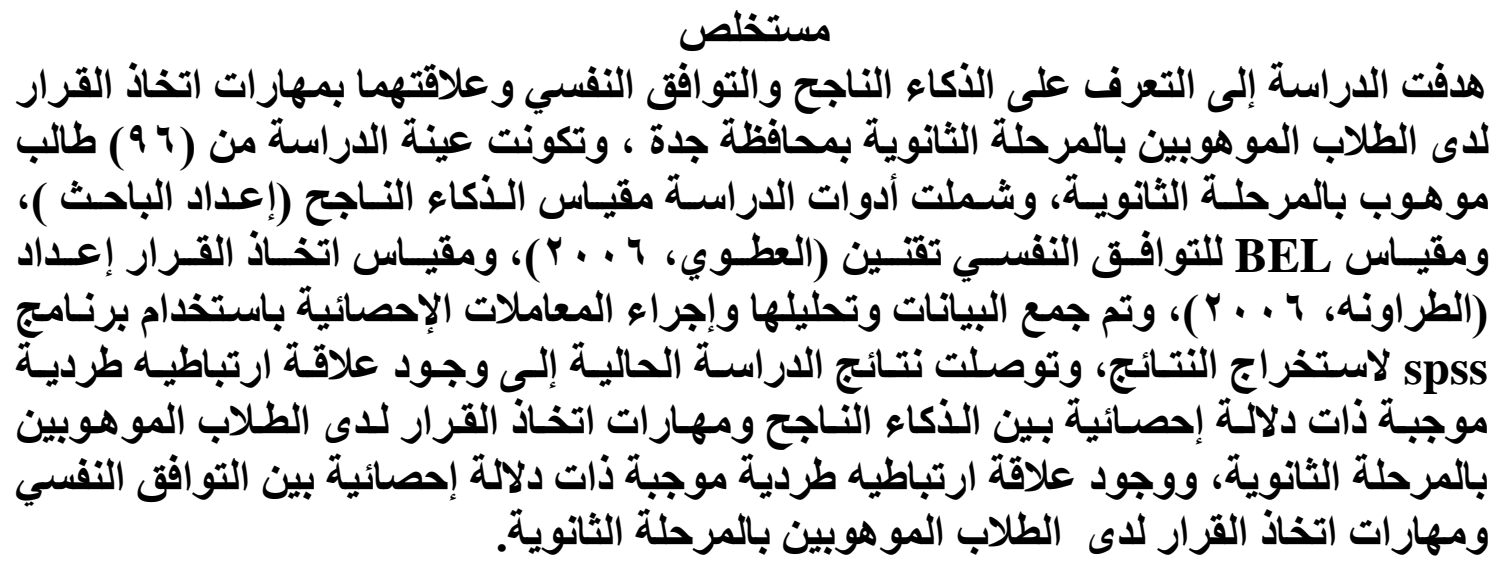

Abstract

The study aimed to identify the Successful Intelligence, psychological compatibility and their relationship to decision making skills among Talented Students at the Secondary Level in Jeddah PROVINCE, and the sample of the study consisted of (96) Talented Students in the secondary school, and included the study tools integrated Successful Intelligence (Setting up the researcher), the BEL measure for psychological compatibility legalization (Atawi, 2006), the decisionmaking measure (Al-Tarawneh, 2006), data collection, analysis and statistical transactions using SPSS program to extract results, and the results of the current study found a positive correlation Statistically significant between the Successful intelligence and decision-making skills of Talented Students at the Secondary Level, and the existence of a positive correlation with a statistically significant correlation between the psychological compatibility and decision- making skills of Talented Students at the Secondary Level. 